\title{
REVISIÓN CRÍTICA DEL ESTATUTO DE RESPONSABILIDAD CIVIL POR DAÑOS NUCLEARES EN CHILE
}

\author{
A CRITICAL REVIEW OF THE CHILEAN CIVIL NUCLEAR LIABILITY \\ REGIME
}

\section{Francisco Javier González Cruz Santiago Acevedo Ferrer ${ }^{* *}$}

\begin{abstract}
RESUMEN: El presente artículo hace una revisión del estatuto de responsabilidad civil por daños nucleares vigente en Chile. El actual régimen está compuesto principalmente por la Ley 18.302 sobre Seguridad Nuclear de 1984 y por la Convención de Viena sobre Responsabilidad Civil por Accidentes Nucleares, ratificada por Chile el año 1989. Aunque en Chile aún no existen plantas nucleares para la generación de energía, es igualmente conveniente analizar de qué manera la legislación chilena protege a los ciudadanos de daños nucleares. Este trabajo no considera las razones de carácter político a favor o en contra de la promoción de la energía atómica. En cambio, este artículo examina críticamente el estatuto de responsabilidad nuclear actualmente vigente en Chile. No cabe duda que, si en el futuro, Chile opta por incluir las fuentes nucleares en su matriz energética, no serán suficientes ciertas aisladas modificaciones legales, sino que será necesario construir un nuevo Régimen Jurídico Energético Chileno que dé cabida a la energía atómica. Para tal evento, en todo caso, será útil conocer a cabalidad el régimen de responsabilidad nuclear actual. Desde este punto de vista, las reformas que este artículo propone podrían ser de utilidad tanto para académicos como para legisladores.
\end{abstract}

Palabras clave: Daño nuclear, responsabilidad estricta, Convención de Viena sobre Responsabilidad Civil por Daños Nucleares, monto máximo de responsabilidad, prescripción.

ABSTRACT: This article reviews the Chilean civil nuclear liability regime. The Nuclear Security Act (Law 18.302), enacted in 1984, and the Vienna Convention on Civil Liability for Nuclear Damage, ratified by Chile in 1989, are the fundamental laws of the current regime. Although Chile has no nuclear power plants, it is still important to analyze how the Chilean legislation would protect citizens from nuclear damages. This paper does not consider the policy reasons for and against the promotion of atomic energy. Rather, it critically examines the current status of the Chilean nuclear regime. Undoubtedly, if in the future Chile chooses to include nuclear sources in its energy mix, it will not be enough to introduce some isolated legal amendments, but it will be necessary to build a new Chilean Energy Regime which includes nuclear energy. In that scenario, though, it will be useful to know and understand how the current nuclear liability regime works. From this point of view, the reforms this

\footnotetext{
Licenciado en Ciencias Jurídicas, Universidad de los Andes; Ayudante de la Cátedra de Derecho Civil de la Facultad de Derecho de la Universidad de los Andes. Correo electrónico: fjgonzalez4@miuandes.cl, fxgonzalezcruz@gmail.com.

** Licenciado en Ciencias Jurídicas, Universidad de Chile; Magíster en Derecho con especialización en Derecho Medioambiental por la Universidad de New South Wales, Sidney, Australia. Correo electrónico: sacevedo@ prieto.cl.
} 
article proposes to the current nuclear liability regime might be helpful to academics and policymakers alike.

Key words: Nuclear damage, strict liability, Vienna Convention on Civil liability for Nuclear Damage, limit on the amount of liability, prescription.

\section{INTRODUCCIÓN}

Se podría decir que la actividad nuclear ha tenido dos nacimientos; los dos en los Estados Unidos de Norteamérica; los dos en el siglo XX. El primer nacimiento fue con fines bélicos y tuvo lugar en un experimento llevado a cabo bajo las graderías de un estadio de fútbol americano en la Universidad de Chicago. El resultado de este proyecto fue haber conseguido la primera reacción nuclear el día 2 de diciembre de $1942^{1}$. Los hallazgos de ese experimento serían implementados tres años más tarde en las dos bombas atómicas lanzadas sobre las ciudades japonesas de Hiroshima y Nagasaki².

El segundo nacimiento de la actividad nuclear puede fijarse once años más tarde, exactamente el día 8 de diciembre de 1953 a las 2:45 p.m. En dicha ocasión, el entonces Presidente de los Estados Unidos, Dwight D. Eisenhower, se dirigió a la Asamblea General de las Naciones Unidas haciendo un llamado al uso de la actividad nuclear para fines pacíficos. En palabras del propio Eisenhower, "Los Estados Unidos buscan más que la mera reducción o eliminación de material atómico con fines militares. No es suficiente con quitar esta arma de las manos de los soldados. Esta arma debe ser colocada en las manos de aquellos que saben cómo despojarla de su carcasa militar y adaptarla para las artes de la paz"3.

El Presidente Eisenhower propuso a continuación la creación de un organismo internacional al alero de las Organización de las Naciones Unidas dedicado a la promoción de la energía atómica. Esta propuesta fue acogida y así, en 1957, se creó el Organismo Internacional de Energía Atómica (OIEA) ${ }^{4}$.

Desde entonces, la energía nuclear ha experimentado un crecimiento significativo ${ }^{5}$. En efecto, actualmente, existen 437 instalaciones de energía nuclear en operación a lo largo del mundo y 65 en construcción ${ }^{6}$. Los reactores operativos aportan un 14\% de la electricidad producida en toda la tierra ${ }^{7}$. Los países que más han desarrollado la energía nuclear

\footnotetext{
1 Hunter et al. (2007) p. 983.

2 Un breve e interesante estudio sobre la vinculación entre la ciencia nuclear y la política, remontándose a los orígenes más remotos de la ciencia nuclear, ha sido realizado por el académico español Rafael CARo MANso (1995) pp. 87-109.

3 Eisenhower (1953).

$4 \mathrm{Al}$ año siguiente de la creación de la OIEA nació una segunda institución, esta vez bajo el alero de los países pertenecientes a la Organización para la Cooperación y el Desarrollo Económico (OCDE), dedicada a la promoción de la energía renovable: la hoy llamada OECD-NEA (OECD Nuclear Energy Agency).

5 Hidalgo Capitán (2011) pp. 181-182. El boom del desarrollo nuclear estuvo fuertemente influido por la variación del precio del petróleo.

6 IAEA (2012) pp. 10-11. De los 65 reactores en construcción, 26 están siendo construidos en China, 10 en Rusia, siete en India y tres en países de la OCDE (Finlandia, Francia y los Estados Unidos de América).

7 Owen (2011) p. 1.306.
} 
son Francia, Estados Unidos y China ${ }^{8}$. Cabe destacar que, dentro de los países OCDE, Australia es el único que prohíbe, por medio de una ley federal de 1998, la construcción de plantas nucleares, circunscribiendo su uso a fines exclusivamente medicinales 9 .

Chile, en cambio, aún no cuenta con instalaciones nucleares para la producción de energía. Las únicas dos instalaciones son de carácter experimental, y tienen por finalidad realizar investigaciones en las áreas de medicina, industria, agricultura, minería y alimentación. El Reactor Nuclear La Reina (Santiago) tiene una capacidad instalada de cinco megavatios (MW) y el Reactor Nuclear Lo Aguirre (ubicado a 28 kilómetros de Santiago) tiene el doble de capacidad ${ }^{10}$.

En todo caso, pese a que Chile y Australia tienen un desarrollo nuclear similar (solo con fines experimentales o de investigación), entre estos dos países existe una diferencia substancial: Chile no ha adoptado una política antinuclear. Muy por el contrario, en Chile existe un régimen jurídico vigente que regla la actividad nuclear; régimen que está compuesto tanto por normas legales así como por tratados internacionales ratificados por Chile y que se encuentran vigentes.

En cuanto al apoyo por parte de la opinión pública, la actividad nuclear gozó de gran popularidad a nivel mundial en la primera etapa de su desarrollo (décadas del 50 al 70). Sin embargo, en la década siguiente, los accidentes nucleares de Three Mile Island en los Estados Unidos en 1979 y de Chernóbil en la actual Ucrania en 1986, levantaron serias interrogantes acerca de la conveniencia de promover el uso de energía nuclear para satisfacer la creciente demanda energética ${ }^{11,12}$.

Durante la última década, en todo caso, la energía nuclear ha despertado nuevamente la atención de académicos y políticos, quienes comenzaron a mirar, una vez más, con buenos ojos la energía nuclear ${ }^{13}$. En efecto, siendo la energía nuclear bastante baja en emi-

8 Una clarificadora introducción acerca del desarrollo de la energía nuclear en el mundo (con especial énfasis en Europa) y del debate nuclear en Chile, ha sido publicada en esta misma revista en el año 2010: OLIVARES (2010) pp. 429-433.

9 En efecto, la "1998 Australian Radiation Protection and Nuclear Safety Act" señala expresamente en su sección 10(1)(b): "(1) Nothing in this Act is to be taken to authorise the construction or operation of any of the following nuclear installations: (...)

(b) a nuclear power plant; (...)”.

10 Comisión Chilena de Energía Nuclear.

11 Rosa y Rice (2004) pp. 186-187. Este trabajo versa específicamente sobre las percepciones de la opinión pública respecto del desarrollo de la energía nuclear en Estados Unidos. Es interesante observar que la oposición a la energía nuclear experimentó un primer gran crecimiento después del accidente nuclear en Estados Unidos de Three Mile Island en 1976 (de un 30\% a un 45\%). En 1981 (y debido a la política armamentista nuclear bajo la Presidencia de Ronald Reagan, la oposición a la energía nuclear experimentó un dramático aumento de un $40 \%$ a un 54\%. Después de Chernóbil, la oposición a la energía nuclear en Estados Unidos llegó aproximadamente al $70 \%$.

12 Fernández de Gatta Sánchez (2007) pp. 1-2. Este autor hace ver cómo la toma de conciencia general sobre el problema ambiental puede situarse en las décadas del 60 y 70.

13 Kessides (2010) p. 3.849. En el mismo sentido, Olivares (2010) p. 432. Véase también, TeräväINEN et al. (2011) pp. 3.434, 3.436, 3.437. Este último trabajo consiste en un análisis comparativo del debate nuclear en Finlandia, Francia y el Reino Unido. Una característica común en los tres países es el argumento de que la energía nuclear es necesaria para combatir el cambio climático. En este sentido, son ilustrativas las palabras, citadas en ese artículo, del entonces Secretario de Energía y Clima en la Cámara de los Comunes del Reino Unido en 
siones de gases de efecto invernadero, esta fuente aparecía como una atractiva, eficiente y económica alternativa a la generación de energía con combustibles fósiles, ayudando de esta manera a combatir el cambio climático.

En términos de contaminación de dióxido de carbono, la diferencia entre combustibles fósiles y nuclear es muy considerable. Así, mientras la producción de un kilovatio hora $(\mathrm{kW} / \mathrm{h})$ de electricidad a partir de carbón genera el equivalente a entre 960 y 1.050 gramos de dióxido de carbono (960-1050 gCO2e), la producción del mismo kW/h de electricidad a partir de material nuclear genera solo $66 \mathrm{gCO} 2 \mathrm{e}^{14,15}$.

Sin embargo, y pese al sustantivo aporte que la energía nuclear podría significar para combatir el cambio climático, el accidente de Fukushima del 11 de marzo de 2011 produjo un fuerte revés en esta nueva corriente que favorecía el robustecimiento de la energía nuclear. Si bien es muy pronto para evaluar la magnitud del accidente de Fukushima, existen contundentes indicios que demuestran que este está muy lejos de alcanzar la intensidad del accidente de Chernóbil.

En primer lugar, a diferencia de Chernóbil, en que no intervino un fenómeno natural, las instalaciones nucleares japonesas fueron expuestas a una combinación de eventos naturales sin precedentes. Fukushima fue sacudida por un terremoto de magnitud 9,0 escala de Richter (similar al ocurrido en Chile 12 meses antes que alcanzó los 8,8 grados). A lo anterior se añadió un maremoto sin precedentes. La masa de agua que azotó las instalaciones nucleares ubicadas en la costa de Fukushima tenían aproximadamente 15 metros de altura ${ }^{16}$. Es necesario hacer presente que las plantas nucleares de Fukushima sí estaban diseñadas contra maremotos, pero solamente para resistir olas de 5,7 metros y no de $15^{17}$.

La segunda importante diferencia entre los accidentes de 1986 y 2011 es que en Chernóbil falló el propio reactor nuclear. En Fukushima no fallaron directamente los reactores, sino los sistemas de enfriamiento de los mismos, los que colapsaron tras el maremoto, permitiendo que el material radioactivo superara los $2.800^{\circ} \mathrm{C}^{18}$.

noviembre de 2009: "As a country, we need nuclear, renewables, and clean coal... They are necessary for security of supply, tackling climate change and the future of our economy". Por su parte, en Francia, el argumento a favor de la necesidad de la energía nuclear tiene el componente adicional de que, actualmente, más de un 78\% de la electricidad doméstica proviene de fuentes nucleares. En este contexto, se entienden de mejor manera las palabras del Presidente Sarkozy en 2010 citadas en ese artículo: "There is no single serious person who could think that we can fulfil our objectives by using only renewable energy sources".

14 Sovacool (2008) pp. 2951, 2960.

15 Codarech (2006) p. 313. No obstante la conveniencia de la energía nuclear por el incremento continuado de los precios del petróleo y por la necesidad de reducir las emisiones de CO2, este autor hace ver que la "posible contribución a estos dos problemas es limitada y que se ve contrarrestada por otros inconvenientes que la desaconsejan. Entre ellos, la cuestión de los residuos, la seguridad y la proliferación nuclear, pero también sus aspectos económicos y financieros. La energía nuclear es muy intensiva en capital y su viabilidad depende, en buena medida, de la evolución de las tasas de interés. En las condiciones actuales, la reactivación nuclear requeriría una apuesta gubernamental decidida, con un retorno a politicas de planificación energética incompatibles con la liberalización llevada a cabo en la última década".

16 OECD-NEA (2011a) pp. 6, 9. Véase también, BBC (2011).

17 Davies (2011) p. 1.942.

18 OECD-NEA (2011a) p. 6. Véase también, Davies (2011) pp. 1.941-1.942. 
En tercer lugar, las mediciones más recientes indican que tanto la radiación liberada como el área afectada en Japón equivalen aproximadamente a un 16\% de la radiación y área afectada con ocasión del desastre de Chernóbil ${ }^{19}$.

Finalmente, en términos de víctimas fatales, en Chernóbil ascendieron al menos a 64 y en Fukushima hasta ahora no las ha habido ${ }^{20}$.

Con todo, es un hecho irrefutable que, con posterioridad a este accidente en Japón, la energía nuclear ha quedado nuevamente en entredicho, agudizándose el debate entre detractores y promotores de la energía nuclear ${ }^{21}$. Ahora bien, el impacto de este accidente en las políticas energéticas de distintos países ha sido también disímil. Así, en Alemania, el gobierno de la Canciller Ángela Merkel anunció a los pocos días del accidente el cierre de siete plantas nucleares ${ }^{22}$. Tres meses más tarde, el Parlamento alemán acordó la supresión definitiva de las restantes 10 plantas nucleares alemanas para el año $2022^{23}$, eliminando así por completo las fuentes nucleares de su generación energética.

Por contraste, la administración del Presidente Obama instó a aumentar la seguridad de las plantas nucleares americanas, expresando claramente que los Estados Unidos de Norteamérica seguirá contando con la energía nuclear como parte integrante de su matriz energética ${ }^{24}$.

Uno de los aspectos que es ineludible discutir con posterioridad a un accidente de la magnitud de Fukushima, es revisar con detención de qué modo la legislación de cada país regula los eventuales daños provenientes de un accidente nuclear y con qué herramientas cuentan las víctimas para conseguir el resarcimiento de sus perjuicios.

El presente trabajo consiste precisamente en una revisión crítica al estatuto de responsabilidad civil extracontractual por daños nucleares vigente en Chile. El capitulo 2 de este trabajo describe brevemente la legislación nuclear aplicable en Chile, la que está compuesta tanto por tratados internacionales, leyes, decretos y reglamentos. El capitulo 3 señala los elementos y características del régimen de responsabilidad por accidentes nucleares en la legislación chilena. El capitulo 4 examina con mayor detención tres aspectos específicos de este régimen de responsabilidad: la extensión del daño indemnizable en materia de daños nucleares (4.1.), la limitación legal de responsabilidad por accidentes nucleares (4.2.) y la prescripción de la acción de responsabilidad (4.3.). La última parte de este trabajo (capitulo 5) sugiere reformas al régimen de responsabilidad por accidentes nucleares vigente en Chile tanto en las tres áreas mencionadas precedentemente (extensión del daño indemnizable, limitación de responsabilidad y prescripción), así como en el área de la prevención del daño. Estas sugerencias podrían ser de utilidad tanto para académicos como para legisladores en el evento que Chile decida promover la introducción de energía nuclear en su matriz ener-

19 BBC (2011). Véase también, IAEA (2011) pp. 30-31.

20 OECD-NEA (2011a) pp. 8, 9. Véase también, BBC (2011).

21 Davies (2011) p. 1.937-1.939.

22 The Guardian (2011).

23 Davies (2011) p. 1.949.

24 Davies (2011) pp. 1.952-1.954. 
gética. Finalmente (capitulo 6), se enumerarán las principales conclusiones a las que arriba el presente artículo.

\section{NORMAS APLICABLES EN MATERIA DE RESPONSABILIDAD NUCLEAR}

En términos generales, podemos señalar que el régimen jurídico nuclear chileno es bastante completo y complejo. Está compuesto por normas de variada naturaleza, tales como tratados internacionales multilaterales ${ }^{25}$, acuerdos bilaterales de cooperación en la materia firmados con países como Colombia, Argentina Uruguay y el Reino de Tailandia, leyes $^{26}$, decretos y reglamentos ${ }^{27}$.

En el presente capítulo, nos referiremos exclusivamente a las normas que reglan la responsabilidad civil por accidentes nucleares, que son las que nos interesan para efectos de este trabajo. Estas normas están contenidas en la ley 18.302 y la Convención de Viena sobre Responsabilidad Civil por Daños Nucleares.

\subsection{Ley N $\mathrm{N}^{\circ}$ 18.302. Ley de Seguridad Nuclear}

Este cuerpo legal fue publicado en el Diario Oficial el 2 de mayo de 1984 y consta de 67 artículos. Pese a que, en su tramitación, la Junta de Gobierno acordó calificarlo de "Sin Urgencia"28, su promulgación fue relativamente rápida, pues desde el mensaje presidencial hasta su publicación, no alcanzaron a transcurrir dos años ${ }^{29}$.

Los cuatro objetivos primordiales de esta ley $\operatorname{son}^{30}$ : asegurar personas, bienes y medio ambiente; prevenir la apropiación indebida o el uso ilícito de la energía atómica; establecer un sistema de responsabilidad civil por daños nucleares; y velar por el cumplimiento de las obligaciones derivadas de acuerdos y convenios internacionales en los que Chile sea parte.

Del estudio de la historia de la presente ley, es posible sostener que el gobierno de entonces tenía como plan o al menos era su intención subjetiva, la promoción de la energía atómica en Chile. Sin embargo, se advierte que tal intención o plan no era de corto plazo o inminente. Lo anterior queda de manifiesto cuando el Ejecutivo, junto con la necesidad de crear las condiciones para la adecuada promoción de la industria nuclear, deja ver la necesidad de "ponerse al día" o de adecuar la legislación a la realidad existente en nuestro país en materia de actividad nuclear.

Así, en su Mensaje al proyecto, el Presidente señaló: "Las actividades que, en el campo de los usos pacificos de la energía nuclear, se llevan a cabo hoy en nuestro pais requieren de una legislación que debe tener por objeto conciliar el impulso al desarrollo de la energía nuclear con

\footnotetext{
25 Además de la Convención en estudio, Decreto No 1.212, de 1993. Decreto No 272, de 1997. Decreto No 8, de 2005. Decreto No 381, de 2005. Decreto No 1.121, de 1994.

26 Además de la Ley 18.302 en estudio, Ley $\mathrm{N}^{\circ} 16.319$, de 1965.

27 DL No 2.224, de 1978. Decreto No 133, de 1984. Decreto No 87, de 1985. Decreto No 12, de 1985.

28 Honorable Junta de Gobierno de Chile (1982) p. 1.

29 Este proyecto de ley fue presentado mediante oficio $N^{\circ} 911(\mathrm{R})$ de 6 de octubre de 1982, Secretaría de Legislación dirigido a la Secretaría de la Honorable Junta de Gobierno. La publicación de la ley tuvo lugar el 2 de mayo de 1984.

30 Ministerio de Minería (1983).
} 
la protección de las personas, bienes y medio ambiente. Este objetivo no es posible conseguirlo por medio de la legislación vigente, sino que necesariamente debe dictarse una legislación especial, puesto que los problemas que la energía nuclear plantea, frente al Derecho, son nuevos y por lo tanto, las soluciones juridicas deben ser nuevas" 31 .

La referencia a las actividades nucleares que "se llevan a cabo hoy" nos lleva a postular que el gobierno de Chile de entonces consideraba que la sola adecuación de la legislación nuclear, generaría las condiciones propicias para el advenimiento de la energía nuclear en Chile, atendido el desarrollo de la industria nuclear a nivel internacional.

\subsection{Convención de Viena sobre Responsabilidad Civil por Daños NuClEARES}

Históricamente han coexistido dos regímenes jurídicos que han tratado sobre la responsabilidad civil por accidentes nucleares. Estos son el "Convenio sobre Responsabilidad Civil en Materia de Energía Nuclear" (Convenio de París) y la "Convención sobre Responsabilidad Civil por Accidentes Nucleares" (Convención de Viena). Estos dos regímenes son más o menos contemporáneos, pues el Convenio de París fue suscrito el 29 de julio de 1960, mientras que el Convenio de Viena fue suscrito el 21 de mayo de 1963. El Convenio de París fue establecido bajo el auspicio de la Agencia de Energía Nuclear de la OCDE (NEA), mientras que la Convención de Viena fue suscrita bajo el impulso del Organismo Internacional de Energía Atómica (OIEA) ${ }^{32}$.

Los dos tratados internacionales antes mencionados pueden ser considerados como un loable intento de la comunidad internacional de dar a la energía nuclear un uso razonable, pacífico y al amparo del derecho internacional, luego que el mundo entero fuera mudo testigo del enorme potencial bélico y destructivo de este tipo de energía aplicada sobre Hiroshima y Nagasaki.

Previa aprobación de la Honorable Junta de Gobierno de 26 de septiembre de 1989, Chile ratificó la Convención de Viena recién el 23 de noviembre de 1989; tratado que fue promulgado como Ley de la República mediante Decreto Supremo el 8 de enero de 1990, esto es, 27 años después de haber sido adoptada y más de cinco años después de la dictación de la Ley 18.302.

Deteniéndonos en este tratado que ratificó Chile en 1989, se puede afirmar que los redactores de la Convención de Viena tuvieron en mente dos objetivos. El primero consistía en proporcionar a la población civil una protección adecuada frente a posibles daños nucleares. Si bien es cierto que la posibilidad de ocurrencia de un accidente nuclear es (y la historia lo ha ratificado) estadísticamente baja, en caso de verificarse un accidente, los da-

\footnotetext{
31 Presidencia de la República de Chile (1982) p. 1. Énfasis agregado.

32 Esta dualidad de instituciones dedicadas a la promoción de la energía nuclear ha marcado el desarrollo del régimen de responsabilidad por accidentes nucleares desde que existen dos tratados internacionales que versan sobre lo mismo y que nacieron cada cual bajo los auspicios de sus respectivas instituciones. Sin bien estos tratados guardan similitudes, son incompatibles entre sí. La mejor prueba de esto es que ningún país ha ratificado los dos tratados. Solo en 1988 este problema fue en parte solucionado por medio del Protocolo de Entendimiento, que tiene por objetivo permitir a miembros de un país que es parte de la Convención de Viena reclamar por daños provenientes de un país parte de la Convención de París y viceversa.
} 
ños pueden ser muy intensos y extensos (lo que la historia también ha ratificado). El segundo objetivo fue elaborar un régimen jurídico que permitiera incentivar el crecimiento de la industria nuclear, lo que redundaría en beneficio de todas las naciones y sus habitantes, asegurando que el desarrollo de la actividad nuclear no conllevara una carga intolerable de responsabilidad que la hiciera económicamente inviable.

Para conciliar estos dos objetivos ${ }^{33}$, potencialmente conflictivos, la Convención de Viena se funda en los siguientes principios:

El explotador de una planta nuclear es el único responsable de los accidentes que se produzcan en ella. Esta atribución exclusiva de responsabilidad en el explotador simplifica y agiliza cualquier eventual juicio de responsabilidad civil por daños, lo que constituye un importante beneficio para las víctimas, quienes no tendrán dudas sobre la persona contra quien deban intentar su demanda.

La responsabilidad por daños es de carácter objetiva o estricta. Consecuencia necesaria es que el explotador de una planta o instalación nuclear es siempre responsable de los daños que se produzcan a raíz de una accidente nuclear, con independencia de si existe o no negligencia en su actuar, lo que sin duda constituye una nueva ventaja para la víctima de un accidente.

La responsabilidad del operador es limitada en tiempo y en el monto. La Convención de Viena, en todo caso, no fija el monto del límite, dejando esta materia a la discreción de cada país. Pero la Convención señala que tal límite que fije la ley no puede ser inferior a cinco millones de dólares. Con respecto al tiempo, la regla es que el derecho a compensación prescribe si la acción no se presenta dentro de los diez años siguientes al accidente nuclear.

El operador debe obligadamente contar con un seguro o alguna otra garantía financiera equivalente a la cantidad de su responsabilidad.

Regla de competencia: las acciones de indemnización en virtud de los Convenios se limita a los tribunales de la parte en cuyo territorio se produjo el accidente.

\section{ELEMENTOS Y CARACTERÍSTICAS DEL RÉGIMEN DE RESPONSABILIDAD POR DAÑOS NUCLEARES EN CHILE}

Teniendo presente que en Chile hay principalmente dos cuerpos normativos que reglan la responsabilidad civil por accidentes nucleares (la Ley 18.302 de Seguridad Nuclear y la Convención de Viena sobre Responsabilidad Civil por Daños Nucleares), en los párrafos siguientes pasaremos a revisar brevemente los elementos y características más importantes de este régimen de responsabilidad y cómo están recogidos esos elementos y características tanto en la Ley 18.302 como en la Convención de Viena.

\subsection{EsTABLECIMIENTO DE UN RÉGIMEN DE RESPONSABILIDAD ESTRICTA}

El artículo 49 de la Ley 18.302 y el artículo IV.1. de la Convención de Viena establecen que la responsabilidad por accidentes nucleares es estricta u objetiva. Es decir, para

33 Este intento de conciliar los dos objetivos mencionados es entendido por Barros Bourie (2006) como un factor común en el establecimiento de regímenes estrictos con limitación de responsabilidad. p. 479. 
que prospere una acción de indemnización de perjuicios no es necesario probar la culpa o dolo del explotador de la instalación nuclear.

En general, los regímenes de responsabilidad estricta ${ }^{34}$ exigen la concurrencia de los siguientes elementos: existencia de daño, relación de causalidad, y que no se configure en la especie alguna exención de responsabilidad que libere al demandado de la obligación de indemnizar.

\subsection{Hecho imputable}

A diferencia de la responsabilidad por culpa, en la que se exige acreditar que el hecho es imputable al demandado, esto es, que el hecho es suyo ${ }^{35}$, en la responsabilidad estricta se entiende derechamente que todo hecho dañoso es imputable al demandado por la sola razón de encontrarse dentro de la esfera del riesgo asumido por ella al desarrollar la actividad peligrosa. En este sentido, la Ley 18.302 establece en su artículo 50 que el explotador de una instalación, planta, centro, laboratorio o establecimiento nuclear será responsable de los daños "ocasionados por un accidente nuclear que ocurra en ellos" (énfasis agregado). Queda claro, entonces, que es suficiente que el accidente ocurra en la instalación para que se haga responsable al explotador.

La Convención de Viena, a este respecto, es aún más precisa ya que enumera las condiciones que deben concurrir para entender que el hecho es imputable al explotador. Así, el artículo II de la referida Convención exige que el accidente ocurra en la instalación nuclear, que en el accidente intervengan sustancias nucleares procedentes de la instalación nuclear del explotador, o que se originen en tal instalación o que hayan sido enviadas a la instalación nuclear. La Convención regula minuciosamente cuándo debe entenderse que una sustancia nuclear procede, se origina o ha sido enviada a una instalación nuclear.

\subsection{EL DAÑo}

Sin daño, no hay lugar a responsabilidad alguna, ni aun en regímenes de responsabilidad estricta, ya que el daño es condición necesaria de la indemnización ${ }^{36}$.

Tanto la Ley como la Convención definen "daño nuclear" 37 . Sobre esta materia se volverá con detención en el subtitulo 4.1. Sin embargo, es necesario advertir desde ya que el solo hecho de que la Ley y la Convención hayan definido qué ha de entenderse por "daño nuclear" puede ser fuente de problemas.

\footnotetext{
34 Seguiremos en este punto a Barros Bourie (2006) pp. 445-446, quien explica que es más conveniente preferir la expresión 'responsabilidad estricta' a la difundida terminología 'responsabilidad objetiva'. La razón que más hace fuerza para preferir la expresión responsabilidad estricta es que, en verdad, la responsabilidad civil (a diferencia de la responsabilidad penal) siempre es objetiva, es decir, al momento de juzgar, el juez no debe estarse a los móviles internos que llevaron al demandado a actuar de determinada forma. Antes bien, toca al juez contrastar la conducta del demandando con el comportamiento que un hombre prudente habría desplegado en esa situación determinada. Y esta labor de contraste es o debiera ser siempre objetiva.

35 Barros Bourie (2006) p. 64.

36 Alessandri Rodríguez (1943) p. 209; Barros Bourie (2006) p. 215; Corral Talciani (2003) p. 137.

37 Artículo $3^{\circ}$ número 14 de la Ley 18.302 y artículo I.1.k) de la Convención de Viena.
} 
Desde un punto de vista práctico, la víctima puede no alcanzar la reparación integral de los perjuicios sufridos si las mermas patrimoniales o extrapatrimoniales efectivamente padecidas no pueden ser encasilladas dentro de los límites de las definiciones legales. Pero más grave aún, una definición deficiente o insuficiente puede atentar contra el principio de la reparación integral consagrado en los artículos 2314 y 2329 del Código Civil ${ }^{38}$. Si a consecuencia de un accidente nuclear la víctima experimenta daños que no pueden calificarse como "daños nucleares", quedarán estos sin indemnización bajo este régimen estricto.

La circunstancia de que determinados daños padecidos por la víctima queden sin indemnización por la razón antedicha, pugna igualmente con lo que se denomina la "teoría del riesgo creado", que es precisamente uno de los fundamentos que se invocan para el establecimiento de los regímenes estrictos ${ }^{39}$. Esta teoría del riesgo creado hace hincapié en el hecho de que quienes desarrollan actividades riesgosas (como la actividad en estudio) deben responder de todos los daños provocados en un "cierto ámbito de riesgos definidos por la ley" ${ }^{40}$. En este sentido, al definir "daño nuclear", la Ley y la Convención no están definiendo el ámbito de riesgos sino que se limitan a señalar cuáles daños podrán ser indemnizados bajo ese régimen. De esta forma, si se siguieran los postulados de la teoría del riesgo creado, la ley debería haberse limitado a señalar que los explotadores responden de todos los daños que se produzcan en el ejercicio de la actividad nuclear.

Un último aspecto que conviene destacar es que dentro de la definición de daño nuclear, tanto la Ley como la Convención mencionan los daños indirectos, introduciendo una novedad en nuestro sistema jurídico. La regla general es que solo se responde de los perjuicios que sean una consecuencia inmediata o directa de hecho del demandado. Así lo ha interpretado la doctrina a partir del artículo 1558 del Código Civil.

La Corte Suprema también ha entendido que no procede la indemnización de los daños indirectos, invocando como fundamento la ausencia de causalidad respecto de es$\operatorname{tos}^{41}$. De esta manera, en materia de daño nuclear, se ha introducido un concepto que hasta entonces era completamente extraño a nuestro ordenamiento jurídico. Volveremos sobre este punto en el subtítulo 4.1. de este trabajo.

\subsection{LiMitACión DEL MONTO DE INDEMNIZACióN}

La Ley chilena de 1984 establece un límite máximo de responsabilidad ascendente a 75 millones de dólares de los Estados Unidos por cada accidente nuclear (artículo 60). La Convención de Viena, por su parte, dispone que el Estado de la instalación podrá limitar la indemnización en una suma no inferior a cinco millones de dólares de los Estados Unidos por cada accidente nuclear (artículo V).

A primera vista todo parece indicar que la Ley y la Convención se complementan en este punto; que el artículo 60 de la Ley 18.302 da aplicación a lo establecido en el artículo

\footnotetext{
38 Un análisis sobre el contenido y alcance de la expresión "reparación integral del daño", en Gonzalo Ruz LÁRTiga (2008).

39 Corral Talciani (2003) pp. 219-220.

40 Barros Bourie (2006) p. 446.

41 Corte Suprema (1953).
} 
V de la Convención de Viena, fijando el límite máximo de indemnización en 75 millones de dólares.

Sin embargo, se deben tener en consideración dos circunstancias: que la Ley 18.302 es cinco años anterior a la ratificación que dio Chile a la Convención, y que la ratificación efectuada por Chile a la Convención no fue pura y simple. En efecto, respecto del artículo V, el Estado de Chile efectuó una declaración interpretativa ${ }^{42}$ que señala que nada obsta a que se persiga la reparación integral de los daños por sobre el límite máximo establecido en la ley chilena. Teniendo en cuenta estas dos consideraciones (que el tratado sería una ley posterior y que Chile efectuó una declaración interpretativa a este artículo V) podría postularse que esa declaración interpretativa derogó el límite máximo de responsabilidad en Chile que establecía la Ley 18.302.

La discusión sobre el particular es altamente relevante y será nuevamente abordada en el subtítulo 4.2. de este artículo. Por ahora, basta con señalar que, en general, los regímenes de responsabilidad estricta u objetiva suelen incorporar límites al monto de indemnización, y esto con el fin de no inhibir el desarrollo de la actividad riesgosa. En este sentido la Ley 18.302 y la Convención así lo hicieron.

\subsection{LA RELACiÓN DE CAUSALIDAD}

El requisito de la relación de causalidad aparece expresamente contenido en la definición legal de "accidente nuclear" cuando se indica que se entiende por tal "cualquier hecho o sucesión de hechos que, teniendo un mismo origen, hayan causado daños nucleares" $\left(\operatorname{art} .3^{\circ} \mathrm{n}^{\circ}\right.$ 13 Ley 18.302).

La relación de causalidad es la unión entre dos eventos. En el caso que nos ocupa, el accidente nuclear y el daño nuclear. Esta relación de causalidad implica que el explotador solo responde bajo el estatuto estricto respecto de daños que se encuentren dentro del ámbito de la actividad riesgosa que desarrolla. En consecuencia, el explotador no responderá de manera estricta por daños ocurridos fuera de esa esfera. Así por ejemplo, si el explotador de una planta nuclear emite ruidos molestos que dañan la tranquilidad de sus vecinos, el explotador no responderá estrictamente sino con arreglo al estatuto general de responsabilidad por culpa del Código Civil.

La relación de causalidad así entendida, circunscribe el ámbito de aplicación del estatuto de responsabilidad por accidentes nucleares a la esfera o ámbito de riesgo inherente a la actividad nuclear. En palabras de Barros "en la medida que el criterio de atribución de responsabilidad estricta es el riesgo definido por la ley, el principio subyacente es que solo deben ser reparadas las consecuencias dañosas que se sigan de ese preciso riesgo" 43 .

\footnotetext{
42 Para algunos autores, las declaraciones interpretativas que un Estado hace a un tratado son una especie de reserva. Para la Comisión de Derecho Internacional, en cambio, las declaraciones interpretativas deben excluirse de la definición de reserva de la Convención de Viena sobre Derecho de los Tratados, desde que aquellas no excluyen ni modifican los efectos jurídicos de una disposición de un tratado sino que solo atañe al modo de interpretar una determinada disposición de un tratado. Monroy (1978) p. 58.

43 Barros Bourie (2006) p. 475.
} 
La Convención de Viena sobre Responsabilidad Civil por Daños Nucleares, por su parte, contiene idéntica definición de "accidente nuclear" a la establecida en la Ley 18.302 de tal manera que todo lo dicho anteriormente es perfectamente aplicable.

Tras su ratificación y promulgación, la Convención no alteró ni complementó el estatuto chileno en este aspecto.

\subsection{EXENCIONES DE RESPONSABILIDAD}

La Ley 18.302 sobre accidentes nucleares contempla casos precisos en que el explotador está exento de responsabilidad por daños nucleares. Dentro de tales hipótesis no se contempla el caso fortuito. Así, si el accidente nuclear se origina a consecuencia de un terremoto o maremoto o ambos (como en Fukushima), el explotador sí será obligado a responder de las consecuencias dañosas que se generen.

Las exenciones de responsabilidad están consagradas en el artículo 56 de la Ley 18.302 y solo son tres: las hostilidades de conflicto armado exterior, la insurrección y la guerra civil. La Convención de Viena, por su parte, establece las mismas causas de exención de responsabilidad (artículo IV.3.a).

Es interesante notar que, respecto de catástrofes naturales de carácter excepcional, la Convención señala que los explotadores sí son responsables de los daños que se ocasionen por esta causa, salvo en cuanto la legislación del Estado de la instalación establezca lo contrario. En el caso de Chile, la Ley expresamente establece que el explotador sí responde del caso fortuito o fuerza mayor. En consecuencia, no hay lugar a dudas acerca de la responsabilidad de los explotadores por accidentes nucleares causados por maremotos o terremotos, eventos que, por lo demás, no son extraños a la historia de nuestro país.

\subsection{Culpa de la víctima}

El derecho común chileno, específicamente el artículo 2330 del Código Civil, confiere al juez la facultad de reducir la indemnización correspondiente al demandante si este se expuso imprudentemente al daño. La Ley 18.302 nada dice respecto de esta situación.

Es posible argumentar en todo caso que el artículo 2330 del Código Civil sí puede ser invocado ya que el Título XXXV del Libro IV del Código Civil es el estatuto general y supletorio y no existe disposición especial en la Ley de Seguridad Nuclear que vuelva inaplicable tal precepto.

La Convención de Viena, por el contrario, establece expresamente la facultad de moderar (e incluso eliminar por completo) la indemnización a la víctima. En efecto, el artículo IV.2. dispone: "Si el explotador prueba que la persona que sufrió los daños nucleares los produjo o contribuyó a ellos por negligencia grave o por acción u omisión dolosa, el tribunal competente podrá, si asi lo dispone su propia legislación, exonerar total o parcialmente al explotador de su obligación de abonar una indemnización por los daños sufridos por dicha persona" (énfasis agregado).

Estimamos que la norma recién citada no confiere a los tribunales chilenos (cuando ellos son los competentes para conocer de la acción de daños nucleares) la facultad de exonerar totalmente al explotador de su obligación de indemnizar. La razón radica en que la Convención se remite a la legislación del tribunal competente (en el caso propuesto, la 
legislación chilena); y la legislación chilena no confiere al juez la facultad de exonerar totalmente al demandado sino solo de reducir el monto indemnizatorio si la víctima se expuso al daño imprudentemente.

\subsection{GARANTÍA FINANCIERA}

La Ley 18.302 establece que todo explotador deberá caucionar su responsabilidad mediante la contratación de un seguro u otra garantía por el límite máximo establecido en el artículo 60, es decir, por 75 millones de dólares (artículo 62). Al mismo tiempo, el artículo 65 dispone que si el explotador no puede caucionar total o parcialmente su actividad, podrá solicitar la garantía del Estado. El Estado queda facultado para conceder o no tal garantía.

La Convención de Viena, por su parte, establece una disposición análoga a la de la Ley 18.302 pero con una diferencia. Esta consiste en que, de la redacción del artículo VII de la Convención de Viena, se puede inferir que el Estado estaría obligado a otorgar esta garantía si el explotador no puede obtenerla por sí, ya que la Convención emplea la frase: "el Estado de la instalación garantizará el pago de las indemnizaciones por daños nucleares" (énfasis agregado).

Sin embargo, al ratificar la Convención, Chile hizo expresa reserva a este artículo en los siguientes términos: "El Estado de Chile formula expresa reserva respecto del artículo VII en el sentido de que cuando el explotador no pueda obtener total o parcialmente un seguro que cubra su responsabilidad, la garantía del estado solamente será otorgada para la parte no cubierta por el seguro o para su totalidad, en los casos y condiciones previstos por el régimen juridico chileno".

De esta manera, a la luz de la reserva efectuada por Chile la norma del artículo 65 de la Ley 18.302 conserva plena vigencia. Esto se traduce en que el Estado de Chile es soberano para conceder o denegar la mencionada garantía estatal.

\subsection{LA PRESCRIPCIÓN}

El artículo 65 de la Ley 18.302 establece que el plazo de prescripción es de diez años, contados desde la fecha en que ocurrió, o se denunció por un inspector, el accidente nuclear.

El artículo VI de la Convención establece una norma equivalente, señalando que el derecho a ser indemnizado se extinguirá si no se entabla la acción dentro del plazo de diez años "a contar desde la fecha en que se produjo el accidente nuclear".

Por la singular importancia que reviste la prescripción, este tema será examinado con mayor profundidad en el subtítulo 4.3. de este trabajo.

\section{ANÁLISIS DE ALGUNOS ASPECTOS ESPECÍFICOS DEL RÉGIMEN DE RESPONSABILIDAD POR DAÑOS NUCLEARES EN CHILE}

El presente capítulo se detiene con especial atención en tres aspectos específicos del estatuto chileno vigente: la extensión del daño indemnizable, la limitación de responsabilidad y la prescripción. Estos aspectos revisten un alto interés y, a juicio de estos autores, merecen ser considerados por nuestro legislador como posibles áreas de reforma. 


\subsection{EXTENSión DEL DAÑo INDEMNizABLE: EL "DAÑo NUCLEAR"}

Resulta oportuno a estas alturas examinar los daños indemnizables bajo la normativa especial de la Ley 18.302. Es necesario entender que, en principio, no cualquier daño causado por un accidente nuclear podrá ser subsumido bajo este régimen estricto. En efecto, del universo de potenciales daños que puedan producirse con ocasión de un accidente nuclear, el legislador ha definido con bastante detalle cuáles daños serán reparables en virtud de este régimen. A estos el legislador les llama "daños nucleares". En otras palabras, y aunque suene paradójico, no todo daño provocado por un accidente nuclear es un "daño nuclear" para efectos de esta ley.

La conceptualización resulta clave, porque determina que, en una suerte de ficción legal, todo lo que no esté contenido en el concepto de "daño nuclear" no estará regido por las normas de responsabilidad estricta. El artículo $3^{\circ} \mathrm{n}^{\circ} 14$ de la Ley $\mathrm{N}^{\circ} 18.302$ define daño nuclear del siguiente modo:

Artículo $3^{\circ}$ número 14. Daño Nuclear:

a) La pérdida de vidas humanas, las lesiones corporales, somáticas, genéticas y síquicas que afecten a las personas, y los daños y perjuicios que se produzcan en los bienes como resultado directo o indirecto de las propiedades radioactivas o de la combinación de estas con las propiedades tóxicas, explosivas u otras propiedades peligrosas de los combustibles nucleares o de los productos o desechos radioactivos que se encuentren en una instalación o de las sustancias nucleares que procedan o se originen en ella o se envíen a ella.

b) La pérdida de vidas humanas, las lesiones corporales, somáticas, genéticas y síquicas que afecten a las personas, y los daños y perjuicios que se produzcan como resultado directo o indirecto de radiaciones que se encuentren dentro de una instalación nuclear.

La definición legal recién transcrita, que es similar a la del artículo I.1.k) de la Convención de Viena, nos permite ahondar en cuatro aspectos relativos al daño:

En primer lugar, la definición no menciona expresamente el daño moral como partida indemnizable. En doctrina, el concepto de daño moral es amplísimo y ha sido clasificado en más de 40 partidas $^{44}$. Con todo, se aprecia que algunas de las hipótesis que contempla la definición transcrita sí pueden catalogarse como daños morales o extrapatrimoniales.

Así, el daño psíquico que menciona la definición, puede catalogarse como un verdadero daño emocional ${ }^{45}$, típicamente conocido como el "pretium doloris". Este daño psíquico puede comprender perfectamente la amargura, la aflicción o la tristeza causada por el hecho ilícito.

Ahora, si bien pareciera que la ley no incluye otra partida de daño moral en su definición, debe tenerse en consideración que la definición transcrita sí hace referencia a las lesiones corporales. Las lesiones corporales pueden entenderse primariamente como un daño

\footnotetext{
44 Barros Bourie (2007) pp. 289-290.
}

45 Corral Talciani (2003) p. 155. 
patrimonial, reparable con la compensación de los costos médicos en que debió incurrir la víctima para repararlos (en su vertiente como daño emergente) o por la compensación de lo que la víctima dejó de percibir en su período de invalidez (en su vertiente como lucro cesante).

Sin embargo, la doctrina más reciente postula que las lesiones corporales pueden también revestir el carácter de daño moral o extrapatrimonial. En este sentido, la lesión corporal no se examina exclusivamente en su dimensión patrimonial (como lo serían los costos médicos o las ganancias no percibidas a raíz de la lesión), sino también en su dimensión aflictiva de esa misma lesión corporal que hace más gravosa la existencia ${ }^{46}$. A su turno, la jurisprudencia ha entendido últimamente que en las lesiones corporales concurren tanto un daño patrimonial como uno extrapatrimonial ${ }^{47}$.

En cualquier caso, estimamos que la definición es deficiente por cuanto al no incluir expresamente el daño moral o extrapatrimonial como partida autónoma de indemnización, hará inviable o al menos dificultará ${ }^{48}$ la reparación de este tipo de daños cuando revistan caracteres "meramente morales" ${ }^{49}$, es decir, cuando no tengan a su vez una repercusión patrimonial.

En segundo término, se echa en falta en la definición una referencia expresa al lucro cesante como partida indemnizable. Sin embargo, tal como se señaló recién, un entendimiento amplio del concepto de lesión corporal, permite incorporar el lucro cesante como partida indemnizable. Se entenderá, pues, que la lesión corporal tuvo un impacto directo en la productividad de la víctima, quien, por ejemplo, no pudo llevar a cabo su negocio durante determinado tiempo, lo que la habría privado de sus ganancias durante su invalidez.

En tercer lugar, la definición transcrita hace expresa referencia a daños indirectos. Es posible entender, entonces, que a partir de la promulgación de esta ley, en Chile no solo se responde por los perjuicios directos provocados por un accidente nuclear, sino también por los indirectos. Lo anterior constituye una excepción única en nuestro sistema de responsabilidad, pues la doctrina civil chilena ha expresado en forma unánime y pacífica que solo se responde de los daños directos ${ }^{50}$. En cualquier caso, en la práctica será difícil configurar la indemnización de los daños indirectos, por cuanto la víctima deberá probar igualmente la relación de causalidad entre el accidente nuclear y el daño ${ }^{51}$.

\footnotetext{
46 Barrientos Zamorano (2008) p. 94. Barros Bourie (2007) p. 290. Corral Talciani (2003) p. 156.

47 Corte Suprema (2012) considerando $27^{\circ}$. Corte Suprema (2009a) considerando $7^{\circ}$. Corte Suprema (2009b) considerando $21^{\circ}$. Corte Suprema (2006) considerando $27^{\circ}$.

48 Decimos “o al menos dificultará” pues en el parecer de Domínguez Hidalgo (2000) la reparación del daño moral y una interpretación amplificadora de los textos legales en orden a incluirlo, tendría una base constitucional en el artículo 19 números 1 y 4. Además, de conformidad con lo dispuesto en el artículo 6º de la Constitución Política, todos los órganos del Estado, incluyendo por cierto a los tribunales, deben someterse a lo dispuesto en la propia Constitución. p. 360.

49 Barrientos Zamorano (2008) p. 94. Alessandri Rodríguez (1943) p. 225.

50 Corral Talciani (2003) p. 143. Alessandri Rodríguez (1943) p. 233. Abeliuk Manasevich (2001) p. 236.

51 Estimamos que la expresión “indirectos” utilizada por la Ley 18.302 y la Convención de Viena proviene de una deficiente traducción del texto inglés. En efecto, la palabra “indirectos” nos lleva a pensar en la expresión "daños indirectos", esto es, aquella categoría de daños que el derecho común no ampara en ninguna acción in-
} 
Finalmente, se advierte una superposición entre el concepto de "daño nuclear" y daño medioambiental.

La Ley 19.300 define daño ambiental como "toda pérdida, disminución, detrimento o menoscabo significativo inferido al medio ambiente o a uno o más de sus componentes" 52 . Se entiende a su vez por medio ambiente "el sistema global constituido por elemento naturales y artificiales de naturaleza física, química o biológica, socioculturales y sus interacciones, en permanente modificación por la acción humana o natural y que rige y condiciona la existencia y desarrollo de la vida en sus múltiples manifestaciones" 53 .

Así las cosas, en el evento de que un accidente nuclear produzca un daño medioambiental, surgirá la duda sobre qué régimen debe ser aplicado. Aunque no pretendemos zanjar definitivamente esta discusión, creemos que podrían preferirse las reglas propias de los accidentes nucleares, ya que el régimen estricto instituido para los accidentes nucleares manifiesta una intención del legislador de subsumir el riesgo propio de una actividad muy particular (la actividad nuclear) a ciertas reglas estrictas que, en definitiva, serán más ventajosas para la actividad probatoria de la víctima ${ }^{54}$.

\subsection{LÍmites AL MONTO DE INDEMNIZACión}

En regímenes de responsabilidad estricta es una práctica común que la ley establezca límites legales al monto de indemnización. El principal argumentos que se esgrime a favor del establecimiento de estos límites es la promoción de la respectiva actividad. Se sostiene que los potenciales desarrolladores de tales actividades riesgosas se verían inhibidos a emprenderlas si estuvieran expuestos a responder ilimitadamente por los daños que puedan causar $^{55}$.

demnizatoria. Los "daños indirectos" del derecho continental son el correlato de los "consequential damages" en el common law. Sin embargo, el texto inglés de la Convención de Viena no emplea en ningún momento la expresión "consequential damages". Por el contrario, el texto inglés señala en el Artículo I.1.k.i: "Nuclear damage' means -loss of life, any personal injury or any loss of, or damage to, property which arises out of or results from the radioactive properties (...)" (énfasis agregado). El pasaje equivalente en castellano señala: "Por 'daños nucleares' se entenderá: la pérdida de vidas humanas, las lesiones corporales y los daños y perjuicios materiales que se produzcan como resultado directo o indirecto de las propiedades radioactivas (...)" (énfasis agregado). De la apreciación comparada de los dos textos se obtiene que la palabra "indirectos" no se condice con el texto inglés. En todo caso, el hecho de que el texto castellano emplee esa expresión es decidor ya que amplía enormemente la categoría de daños nucleares indemnizables incluyendo, por primera vez en nuestra legislación, los indirectos. Estimamos que una traducción más acorde con el texto inglés podría haber empleado las expresiones "daños materiales que surjan o resulten de las propiedades radioactivas (...)". En todo caso, en estricto rigor no cabe hablar de traducciones en estos tratados, puesto en la Organización de las Naciones Unidas, tanto el inglés como el castellano (junto con el árabe, el chino, el francés y el ruso) son idiomas oficiales.

52 Ley No 19.300, de 1994, art. 2 letra e).

53 Ley No 19.300, de 1994, art. 2 letra ll).

54 La ley 18.302 soluciona expresamente el cúmulo de responsabilidades respecto de los daños sufridos por las personas que trabajan en una instalación nuclear. Dice que a esas personas se les aplicará el régimen de seguridad social, o de accidentes del trabajo o enfermedades profesionales y no serán indemnizados con arreglo a la Ley de Seguridad Nuclear.

55 Barros Bourie (2006) p. 479. 
En Chile, los estatutos de responsabilidad estricta vigentes y al mismo tiempo establecen límites legales son la responsabilidad del explotador de aeronaves por daños ocasionados por accidente aéreo ${ }^{56}$, la responsabilidad por los daños causados por el derrame de hidrocarburos en el $\operatorname{mar}^{57}$ y la responsabilidad proveniente de daños nucleares en estudio.

\subsubsection{Limites a la responsabilidad nuclear en otras jurisdicciones}

En materia de actividades nucleares, el establecimiento de límites legales es una práctica arraigada en muchas jurisdicciones así como también en tratados internacionales.

En los Estados Unidos de América, por ejemplo, se establecen dos límites de responsabilidad para los operadores de reactores nucleares según la capacidad de la planta nuclear, respondiendo hasta un límite de 11,9 billones ó 560 millones de dólares dependiendo de si la capacidad instalada de la instalación es superior o inferior a $100 \mathrm{MW}^{58}$.

Francia, por su parte, establece un límite de responsabilidad ascendente a 133,3 millones de dólares. Tratándose de plantas nucleares de bajo riego y actividades de transporte, el límite llega a 33,4 millones de dólares ${ }^{59}$. Italia también establece un límite a la indemnización del operador de instalaciones nucleares que es considerablemente menor al establecido en Francia pues solo llega a 7.9 millones de dólares ${ }^{60}$. Eso sí, tanto Italia como Francia, por el hecho de ser parte del Convenio de París establecen mecanismos que obligan tanto al Estado como a los demás Estados parte del Convenio de París, a reparar daños que superen el límite legal del operador y que no excedan determinado monto. Este mecanismo será explicado en el acápite inmediatamente siguiente.

En Japón y Alemania, por el contrario, la responsabilidad por accidentes nucleares no está limitada, de tal manera que los operadores deberán indemnizar íntegramente los daños causados ${ }^{61}$.

\subsubsection{Limites a la responsabilidad nuclear en tratados internacionales}

Como se indicó más arriba, existen dos entidades internacionales abocadas a la promoción de la energía nuclear. Cada uno de estos organismos ha promovido su propio tratado internacional sobre responsabilidad civil por accidentes nucleares. Tanto el Convenio de París de 1960 bajo el alero de la OECD-NEA, como la Convención de Viena de 1963 bajo los auspicios de la OIEA establecen límites de responsabilidad, eso sí de manera bastante diversa.

El Convenio de París distingue tres capas o estratos de responsabilidad. La primera capa es la que corresponde a la responsabilidad propia del operador y asciende a la suma de no menos de cinco millones de $\mathrm{DEG}^{62}$. Corresponderá a la legislación nacional determinar

56 Ley $\mathrm{N}^{\circ} 18.916$, de 1990, art. 143.

$57 \mathrm{DL} \mathrm{N}^{\circ}$ 2.222, de 1978, art. 145.

58 OECD-NEA (2011b) p. 16.

59 OECD-NEA (2011b) p. 5.

60 OECD-NEA (2011b) p. 8.

61 OECD-NEA (2011b) pp. 6-8.

62 DEG es la sigla para "Derechos Especiales de Giro", que es un activo de reserva internacional del Fondo Monetario Internacional, cuyo valor se calcula actualmente en base a una canasta de cuatro monedas internacionales fundamentales (dólar americano, euro, libra esterlina y el yen japonés). En inglés se les llama Special 
hasta dónde llega el límite de la responsabilidad del operador, sin descender del monto mínimo mencionado. En todo caso el OECD-Steering Committee for Nuclear Energy (el órgano de gobierno de la Agencia de Energía Nuclear) recomendó en 1990 a los países que son parte del Convenio (en adelante, países-parte), limitar la responsabilidad del operador en no menos de 150 millones de $\mathrm{DEG}^{63}$.

La segunda capa cubre los daños que superan el límite anterior (que como hemos explicado varía según decide cada país-parte) y hasta 175 millones de DEG ${ }^{64}$. Esta segunda capa de daños debe ser cubierta por el Estado en que se ubica la instalación nuclear que causó el daño.

Finalmente, el tercer estrato de indemnización cubre los daños que superan los 175 millones de DEG hasta los 300 millones de $\mathrm{DEG}^{65}$. Este último estrato no es originario del Convenio de París y fue añadido por el Convenio de Bruselas, complementario al Convenio de París, adoptado en 1963 (modificado en 1964, en 1982 y en 2004), y consiste en hacer responder a los países-parte por los daños que excedan la responsabilidad del Estado (175 millones de DEG) y hasta 300 millones de DEG. Los países-parte contribuirán a esta deuda en distintas proporciones conforme a una fórmula preestablecida.

Por otra parte, la Convención de Viena es, en este aspecto, más simple que el Convenio de París. Esta exige a las partes contratantes establecer un límite a la indemnización por daños nucleares siempre que este límite no sea inferior a cinco millones de dólares americanos. La Convención de Viena no establece otras capas de indemnización y, en consecuencia, no involucra ni al Estado ni a la comunidad internacional. Como ya se ha señalado, Chile suscribió este tratado en 1963, el que solo fue ratificado en 1989 y promulgado en 1990.

\subsubsection{Limites a la responsabilidad nuclear en la ley chilena}

En Chile, el artículo 60 de la Ley 18.302 establece un límite de responsabilidad comparativamente bajo, que asciende a 75 millones de dólares por cada accidente nuclear. El límite recién señalado es, en todo caso, reajustable según la variación que experimente el dólar entre la fecha de la dictación de la ley y la ocurrencia del accidente nuclear de conformidad con una regla específica que señala la propia ley ${ }^{66}$. Es importante destacar que la

Drawing Rights (SDRs). Al 12 de marzo de 2012, 1 DEG equivalía a USD 1.54. En consecuencia, 5 millones de DEG equivalían a USD 7,7 millones.

63 OECD-NEA (1990) p. 13. Al 12 de marzo de 2012, 150 millones de DEG equivalían a USD 231 millones.

64 Al 12 de marzo de 2012, 175 millones de DEG equivalían a USD 269,5 millones.

65 Al 12 de marzo de 2012, 300 millones de DEG equivalían a USD 462 millones.

66 El artículo 60 de la Ley 18.302 señala a este propósito: "El límite máximo de responsabilidad por daños nucleares en que puede incurrir el explotador por cada accidente nuclear, será el equivalente en moneda nacional de la suma de 75 millones de dólares, moneda de Estados Unidos de América, el que se reajustará automáticamente en el porcentaje de la variación de los Derechos Especiales de Giro del Fondo Monetario Internacional, entre la fecha de esta ley y la del accidente nuclear" (énfasis agregado). En primer lugar, es claro que esta regla especial de reajuste prima por sobre la regla general contenida en el artículo 20 de la Ley 18.010. En segundo lugar, si esta regla se interpreta considerando el valor del dólar respecto de los Derechos Especiales de Giro (DEG), se obtiene el siguiente resultado. El valor del dólar respecto de los DEG a la fecha de la publicación de la ley (2 de mayo de 1984) era de 0,95623 (fuente: http://www.tititudorancea.com/z/fx_xdr_19840502.htm). Por su parte, el valor del dólar respecto de los DEG al 12 de marzo de 2012 es de 0,651179 (fuente: http://www.imf.org/ex- 
Ley 18.302 en estudio fue promulgada con anterioridad a la primera ratificación por parte de Chile de un instrumento internacional relativo a la regulación de responsabilidad por accidentes nucleares.

Así, en 1990, es decir cinco años después de la promulgación de la Ley 18.302, el entonces Capitán General y Presidente de la República de Chile don Augusto Pinochet Ugarte, previa aprobación de la Junta de Gobierno, ratificó y promulgó por primera vez un tratado internacional relativo a la responsabilidad por accidentes nucleares: la ya mencionada Convención de Viena sobre Responsabilidad Civil por Daños Nucleares.

A diferencia de la casi totalidad ${ }^{67}$ de los demás países-parte, la ratificación de Chile de este tratado no fue pura y simple. Chile formuló una declaración interpretativa al artículo $\mathrm{V}^{68}$.

El artículo V de la Convención de Viena versa precisamente sobre el límite de responsabilidad que los Estados pueden fijar en no menos de cinco millones de dólares. La declaración interpretativa señala lo siguiente: "El Estado de Chile declara respecto del artículo $V$ que nada obsta a que, según las reglas o principios de derecho, se puede perseguir la reparación integra de los daños efectivamente producidos en los casos en que tales daños excedieren la limitación establecida por la legislación chilena" (énfasis agregado) ${ }^{69}$.

La lectura conjunta del artículo 60 de la Ley de 1984 y la declaración interpretativa a la Convención de Viena parece dar cuenta de una incompatibilidad insalvable entre estas dos disposiciones. La pregunta que surge, entonces, es la siguiente:

4.2.4. ¿Es posible sostener que la ratificación y promulgación de la Convención de Viena en 1990 haya derogado tácitamente el limite de responsabilidad de la ley 18.302?

Para responder esta interesante pregunta, es necesario dilucidar previamente si es posible que un tratado internacional (posterior) derogue una ley interna (anterior). La Convención sobre Derecho de los Tratados (ratificada por Chile en 1981) define tratado como "un acuerdo internacional celebrado por escrito entre Estados y regido por el derecho internacional, ya conste en un instrumento único o en dos o más instrumentos conexos y cualquiera sea su denominación particular"70. Como se puede advertir, la definición de tratado atiende más a la formalidad de haber sido suscrito por escrito entre Estados, más que al contenido del tratado.

ternal/np/fin/data/rms_mth.aspx?reportType=SDRCV). En consecuencia, entre la dictación de la ley y la fecha actual señalada (12 de marzo de 2012), el dólar americano se ha desvalorizado en un 29,97\%. De esta forma, si se aplicara la fórmula de reajuste propuesta en la ley, se obtiene que el límite máximo de responsabilidad se habría reducido de 75.000 .000 a 52.522 .500 dólares. En todo caso, más adelante se sostendrá que el señalado límite de responsabilidad del artículo 60 ha sido tácitamente derogado en Chile, de tal manera que esta fórmula de reajuste no tendría aplicación práctica.

67 Junto con Chile, el Estado de Israel efectuó una reserva al momento de suscribir este tratado.

68 Junto con la declaración interpretativa en estudio, el Estado de Chile también formuló una reserva al artículo VII de la Convención de Viena.

69 Esta declaración interpretativa figura tanto en el texto del Decreto Supremo $N^{\circ} 18$ que aprobó la Convención como en el instrumento de ratificación depositado por el Estado de Chile en la OIEA.

70 Convención de Viena sobre el Derecho de los Tratados art. 2.1.a). 
A la luz de esta definición, la doctrina más autorizada en la materia enseña que los tratados internacionales pueden tener el rango de ley, dependiendo del contenido del referido tratado. De esta manera, las disposiciones de un tratado tendrá el rango de ley si la materia sobre la que versan todas o algunas de sus disposiciones tiene carácter de ley, de conformidad con la Constitución ${ }^{71}$. La doctrina recién transcrita es plenamente concordante con el artículo 54 número 1 de la Constitución Política. Dicha norma dispone que la aprobación que corresponda al Congreso se rige según los quórum que corresponda de conformidad con el artículo 66. Y el quórum necesario para aprobar un tratado variará dependiendo de la materia sobre la que verse tal tratado. La doctrina sentada es igualmente concordante con lo dispuesto en el inciso cuarto del artículo 54 número 1, en cuanto que exime de aprobación los tratados celebrados por el Presidente de la República en el ejercicio de su potestad reglamentaria. Todo lo expuesto nos permite concluir que la Convención de Viena sobre responsabilidad nuclear sí tiene rango de ley pues versa sobre una materia de ley, de conformidad con lo señalado en el 63 de la Constitución ${ }^{72}$. Por consiguiente, es conceptualmente posible que este tratado haya derogado la ley $18.302^{73}$.

Resuelto lo anterior, la pregunta planteada recobra todo su vigor: ¿̇erogó la Convención el artículo 60 de la ley 18.302? La dificultad de la pregunta nos obliga a recurrir a la historia fidedigna de estos dos cuerpos normativos.

\section{i. Historia de la Ley 18.302}

Durante la tramitación de esta ley, la Secretaría de Legislación de la Junta de Gobierno observó lo siguiente:

El artículo [60] del proyecto ofrece también dudas de orden constitucional, en cuanto limita la responsabilidad del explotador por los daños nucleares causados, a un máximo de US\$ [7]5.000.000 en su equivalente en moneda nacional.

Si el sentido de tal precepto fuere impedir a la víctima que ha sufrido daños por una suma superior a la señalada, cobrar ese mayor perjuicio, la norma sería inconstitucional, porque se lesionaría el derecho del propietario de la acción personal para el cobro de perjuicios por esa mayor suma, contrariando la garantía del derecho de propiedad, reconocida en el $N^{\circ} 24$ del artículo 19 de la Carta Fundamental.

La Secretaría de legislación, sin embargo, no le da esa interpretación a dicho precepto [art. 60]. Por esa razón no lo objeta, ya que entiende que el que sufre perjuicios por daños nucleares por el equivalente en moneda nacional de US\$ [7]5.000.000 o menos, puede recurrir a los preceptos del proyecto en informe, y haciendo uso de

\footnotetext{
71 Silva Bascuñán (2000) pp. 301-302, 333-334.

72 En particular, la Convención regla una materia que es propia de la codificación civil pues regla la responsabilidad extracontractual erigiendo un estatuto independiente y estricto para los accidentes nucleares. De la misma forma, es materia de ley pues establece normas generales y obligatorias en esta materia. Cabe mencionar igualmente que este tratado versa sobre las mismas materias que la Ley 18.302, con la sola diferencia que por su carácter de tratado internacional, dichas normas limitan la soberanía de Chile en sus relaciones internacionales con los demás países-parte.

73 Silva Bascuñán (2000) p. 333.
} 
la responsabilidad objetiva -que lo releva de tener que probar dolo o culpa del deudor-, cobrarlos en la forma que la iniciativa determina. Pero, en el evento de que sus perjuicios sean mayores a dicha suma [US\$ 75.000.000], tiene derecho a cobrarlos, hasta quedar completamente indemnizado del [d]año sufrido, de acuerdo con las reglas generales del derecho, o sea, conforme al Título XXXV del Libro IV del Código Civil, "De los delitos y cuasidelitos" 74 .

\section{ii. Historia de la aprobación, ratificación y promulgación de la Convención de Viena sobre daño nuclear}

La historia fidedigna de la aprobación, ratificación y promulgación de la Convención de Viena da también algunas luces sobre el asunto que nos ocupa.

Conforme dispone el artículo 54 número 1 de la Constitución, correspondía al Congreso la aprobación de este tratado internacional. Ahora bien, quien ejercía en ese entonces dicha función era la Honorable Junta de Gobierno ${ }^{75}$. La aprobación de la Convención de Viena sobre Responsabilidad Civil por Daños Nucleares se efectuó el día 26 de septiembre de 1989. En la respectiva acta se dejó constancia de lo siguiente:

El señor ALMIRANTE MERINO.- El primer punto de la Tabla se refiere a la Convención de Viena sobre Responsabilidad Civil por Daños Nucleares.

¿Hay observaciones al respecto?

(...)

El señor GENERAL MATTHEI.- Había una recomendación de parte de la Tercera Comisión.

El señor GENERAL STANGE.- Sí.

El señor ALMIRANTE MERINO.- Efectivamente, se hace una reserva (sic) ${ }^{76}$, y el Ministerio de Relaciones Exteriores está de acuerdo en mantenerla, en cuanto a la responsabilidad total por los daños que se puedan producir, en especial en el caso actual, pues en estos días se debería dictar una ley sobre cenizas y otras basuras nucleares que los argentinos desean colocar en la Patagonia, en cuanto a los efectos mayores que puedan ocasionar daños nucleares como resultado de la contaminación.

Se podría aprobar el informe con la respectiva reserva (sic).

El señor GENERAL MATTHEI.- Sí.

El señor TENIENTE GENERAL SINCLAIR.- Conforme.

El señor ALMIRANTE MERINO.- Aprobado.

--Se aprueba el proyecto ${ }^{77}$.

74 Secretaría de Legislación de la Honorable Junta de Gobierno (1982) pp. 26-27.

75 De conformidad con el artículo Decimoctavo Transitorio letra D, en relación con el artículo Decimotercero Transitorio de la Constitución Política de la República, la Junta de Gobierno en ese entonces tenía la atribución exclusiva de "aprobar o desechar los tratados internacionales, antes de la ratificación presidencial".

76 Sin perjuicio de que en la presente discusión los miembros de la Honorable Junta de Gobierno emplean la expresión "reserva", es inequívoco que se están refiriendo a la declaración interpretativa propuesta por el Ejecutivo al artículo V de la Convención de Viena, que es el único artículo que trata del límite a la indemnización.

77 Honorable Junta de Gobierno de Chile (1989) pp. 9-10. 
Examinadas las respectivas historias fidedignas de la Ley y de la Convención, estamos en condiciones de responder derechamente la pregunta planteada. A juicio de estos autores, la ratificación de la Convención de Viena sobre Responsabilidad Civil por Daños Nucleares no derogó el límite legal de 75 millones de dólares establecidos en la ley. En abono de esta postura existen dos argumentos:

En primer lugar, al establecer el límite de responsabilidad en 1984, el legislador estimó que tal límite no era absoluto. Por el contrario, se consideraba que un límite absoluto constituiría una vulneración a la garantía constitucional de la propiedad, consagrada en el artículo 19 número 24 de la Constitución. Y solo bajo ese entendimiento no se objetó el límite propuesto. En este sentido, al amparo de la ley 18.302, la víctima siempre podrá ser indemnizada por sobre el límite legal invocando y probado el dolo o la culpa del demandado, respecto de los daños no cubiertos bajo el estatuto estricto.

En segundo y último término, la declaración interpretativa al artículo V de la Convención ha de ser entendida según su naturaleza jurídica, es decir, como una declaración unilateral de un Estado en orden a interpretar una determinada disposición de un tratado ${ }^{78}$. En este sentido, se debe entender que la declaración interpretativa no es una "reserva" ya que no tiene por objeto "excluir o modificar los efectos juridicos de ciertas disposiciones del tratado"79. Así entendida, la declaración interpretativa puede concebirse correctamente como un reconocimiento expreso de aquella interpretación que diera la Secretaría de Legislación de la Junta de Gobierno al artículo 60 de la Ley 18.302.

En conclusión, estimamos que el legislador de 1984 y el Ejecutivo y el legislador de 1989 han tenido una postura consistente en la materia. Para ellos, el límite de responsabilidad solo opera respecto del régimen estricto. Y si la víctima padece perjuicios que superan el límite legal, nada obsta que ella inste por la reparación integral del daño sufrido. Pero en esta hipótesis, pesará sobre la víctima la carga de probar la culpa o el dolo del demandado.

\subsection{Prescripción de la acción de daÑo NUClear}

La acción de daños consagrada en Título XXXV del Libro IV del Código Civil tiene un plazo de prescripción de cuatro años contados "desde la perpetración del acto" (Código Civil, artículo 2332). Esta es la norma general aplicable en los casos de responsabilidad extracontractual.

La interpretación de esta regla ha ido evolucionando en el tiempo, debido a los problemas que ha presentado en su estricta aplicación ${ }^{80}$. El pivote sobre el cual ha girado la controversia y ha dado lugar a dispares opiniones es el concepto de perpetración del acto. Algunos autores han asumido que este consistiría en el hecho generador causante del daño (interpretación literal), mientras que otros han sostenido que es un concepto que debe entenderse sobre todo a la luz del propósito correctivo del daño que se propone la ley (in-

\footnotetext{
78 Monroy (1978) p. 58.

79 Convención sobre el Derecho de los Tratados, art. 2.1.d.

80 Barros Bourie (2006) pp. 922-923.
} 
terpretación finalista). Desde esta última óptica, la perpetración del acto solo se verificaría cuando, además del hecho, se ha producido y manifestado el daño en la víctima ${ }^{81}$.

La discusión no es baladí, porque la aplicación meramente literal de la ley podría conducir a resultados injustos. El problema se presenta cuando los daños se producen o manifiestan con posterioridad al hecho que los causa, reduciendo consecuentemente el plazo de prescripción, en detrimento de la víctima. Incluso podría darse el caso de daños que se manifiesten con posterioridad al plazo de cuatro años, en cuyo caso la acción para reclamar perjuicios nacería prescrita, dejando en la más completa indefensión a la víctima.

La solución finalista que la jurisprudencia ha dado a este problema ha sido reinterpretar el artículo 2332, entendiendo que, solo una vez que se verifique o manifieste el daño, comenzará a computarse el plazo de prescripción ${ }^{82}$. En todo caso, esta interpretación finalista, tiene el inconveniente de pugnar con el tenor literal del artículo 2332. Además, plantea un problema desde el punto de vista de uno de los fines de la prescripción, cual es la certeza jurídica, porque volatiliza el momento de la perpetración del acto, poniéndolo en el a veces caprichoso terreno de las apreciaciones subjetivas. Lo anterior se acentúa aún más si el daño que se manifiesta tardíamente es de carácter meramente moral ${ }^{83}$, cuya verificación responde muchas veces a un estado subjetivo de la víctima.

Estimamos que el problema de fondo radica en que la regla contenida en el artículo 2332 carga con el peso de solucionar situaciones de responsabilidad extracontractual muy disímiles. Esta es la explicación de la interpretación un tanto forzada -pero fundada en un sentido de justicia- a la que ha llegado la doctrina finalista.

Abocándonos al tema que nos ocupa, en materia de daños por accidentes nucleares este agudo problema se resuelve de un modo más simple, pero igualmente insatisfactorio. El legislador ha optado por establecer un plazo de 10 años para ejercer la acción indemnizatoria, contados desde que "ocurrió o se denunció por un inspector el accidente nuclear" (Ley 18.302, artículo 66, énfasis agregado). Por su parte, hemos visto que "accidente nuclear" es definido legalmente como "cualquier hecho o sucesión de hechos que, teniendo un mismo origen, hayan causado daños nucleares” (artículo 13, énfasis agregado). En consecuencia, considerando que el concepto de "daño nuclear" está inmerso en la definición de "accidente nuclear”, concluimos que el plazo solo se podrá contar a partir de que el daño se haya efectivamente producido.

La modalidad empleada por el legislador para computar la prescripción de la acción indemnizatoria por daños nucleares resuelve los inconvenientes antes mencionados. En ese sentido, la técnica empleada conlleva ventajas para la víctima, que tendrá un plazo de 10 años desde que se ha producido el daño nuclear (y por lo tanto lo ha podido conocer) para ejercer las acciones correspondientes. En suma, el plazo de prescripción de la acción de

81 Un análisis exhaustivo de este problema en el Derecho Civil desde distintas perspectivas en los trabajos de Vergara Bezanilla (2011) y Elorriaga de Bonis (2011).

82 Un análisis de la evolución de la doctrina y de la jurisprudencia en este sentido en Barros BourIE (2006) 922-924.

83 Empleando esta expresión en el sentido que la entienden Alessandri Rodríguez (1943) y Barrientos Zamorano (2008). 
daños por un accidente nuclear comenzará a computarse desde que se ha producido efectivamente el daño, nunca antes.

Nos parece que si bien la regla actual tiene ventajas para la víctima, genera el inconveniente de atentar en contra de la certeza jurídica, en perjuicio principalmente de los explotadores de instalaciones nucleares. En cualquier caso, puestos a elegir entre la reparación efectiva de las víctimas y la certeza jurídica de los explotadores de instalaciones nucleares, parece prudente preferir a los primeros. De todas formas, se sugerirá alguna reforma al estado actual de cosas en el capítulo siguiente.

\section{5. ÁREAS DE REFORMA: HACIA UN RÉGIMEN DE RESPONSABILIDAD NUCLEAR MADURO}

La energía nuclear no es una realidad en nuestro país, esto es evidente. En Chile, la actividad nuclear está limitada a investigaciones de carácter experimental en las áreas de medicina, industria, agricultura, minería y alimentación.

Pese al prematuro desarrollo de la actividad nuclear, Chile cuenta con un estatuto de responsabilidad civil por accidentes nucleares desde 1984, complementado por la Convención de Viena sobre Responsabilidad Civil por Daños Nucleares, ratificada y promulgada por Chile en 1990.

El actual Presidente de la República de Chile, en su Mensaje al País de 21 de mayo de 2011, señaló: "Hemos descartado planificar o construir plantas de energía nuclear durante nuestro gobierno. Si avanzaremos en comprender mejor estas tecnologías y en capacitar a nuestros profesionales y técnicos" 84 . Es preciso tener presente que esta declaración fue emitida dos meses después del accidente de Fukushima y, probablemente, respondió a la conmoción mundial que produjo ese accidente. En todo caso, en la línea de la capacitación anunciada por el Presidente Piñera, los gobiernos de Chile y Francia ya habían acordado en octubre de 2010 una declaración conjunta con el objetivo de implementar un programa de formación de capital humano en esta área de desarrollo ${ }^{85}$.

Para el caso que Chile decida en el futuro incorporar la energía atómica a su matriz energética, no cabe duda que serán necesarias no solo ciertas aisladas reformas sino la construcción de un completo nuevo régimen jurídico energético. En ese entendido, estimamos que las reformas que este trabajo sugiere pueden constituir al menos un aporte en la configuración de dicho eventual nuevo régimen.

Solo desde esta perspectiva han de entenderse las reformas que en este apartado se sugieren.

\subsection{REForma EN MATERIA DE EXTENSión DEL DAÑo INDEMNiZAble}

En congruencia con lo mencionado en el apartado anterior en que nos hemos referido a este tema, creemos que el concepto de daño indemnizable debe ser reformado, teniendo como fundamento no tanto las características del daño cubierto por un accidente nu-

84 Piñera Echenique (2011) p. 28.

85 Ministerio de Energía (2011) p. 576. 
clear, cuanto su origen. En otras palabras, el explotador debiera estar obligado a responder de todo daño que sea una consecuencia directa del accidente nuclear, independientemente de las características particulares que dicho daño revista.

El resultado inmediato de seguir esta recomendación será la ampliación de los daños cubiertos, logrando así -al menos conceptualmente- una reparación integral y equitativa de los perjuicios derivados de un accidente nuclear.

\subsection{REFORMA EN MATERIA DE LÍMITE DE RESPONSABILIDAD Y GARANTÍA FINANCIERA}

Como hemos sostenido más arriba, el régimen nuclear vigente en Chile contempla un límite de responsabilidad que asciende a 75 millones de dólares. Puestos en la disyuntiva de abogar por el mantenimiento de este límite o, por el contrario, hacer responder a los explotadores de instalaciones nucleares de un modo estricto e ilimitado, nos inclinamos por derogar derechamente el límite actual. Estimamos que hay al menos cinco razones para sostener lo anterior.

En primer lugar, los límites legales de responsabilidad fueron establecidos hace muchísimo tiempo. Así la ley chilena de 1984 (Ley 18.302) se basó en la Convenciones de Viena y en el Convenio de París, los dos adoptados en los años 60. De esta manera, los límites de responsabilidad no han evolucionado a la misma velocidad que la industria nuclear. En el caso de Chile, el límite de 75 millones de dólares establecido en el artículo 60 de la Ley 18.302 es increíblemente bajo si se tiene en mente un accidente como el de Fukushima que estima pérdidas del orden de 250 billones de dólares ${ }^{86}$.

En segundo término, una modificación de esta naturaleza no iría en contra del texto de la Convención de Viena sobre Daños Nucleares, desde que su artículo V simplemente faculta a los Estados a limitar el monto de la indemnización: "El Estado de la instalación podrá limitar el importe de la responsabilidad”. De esta forma, la derogación del límite que aquí se propone, no sería sino un ejercicio legítimo de una facultad del Estado de Chile al amparo de la Convención.

En tercer lugar, se ha dicho con razón que los límites de responsabilidad son un incentivo perverso ya que en el caso que nos ocupa pueden incentivar a los explotadores de instalaciones nucleares a someterse a riesgos superiores al límite en el entendimiento que nunca serán obligados a responder por daños por sobre ese límite. Por consiguiente, los explotadores no tendrán el más mínimo incentivo a reducir los potenciales daños que superen el límite legal ${ }^{87}$.

En el caso de Chile, este incentivo perverso puede entenderse morigerado. En efecto, tanto la historia de la Ley 18.302 como la declaración interpretativa del Estado de Chile a la Convención de Viena sobre Daño Nuclear, fueron enfáticas en señalar que nada obsta a que la víctima inste por la reparación de daños que superen tales límites conforme a las reglas generales en materia de responsabilidad extracontractual. En cualquier caso, la carga de la prueba que pesaría sobre la víctima para intentar una reparación por sobre el límite

\footnotetext{
86 Cooper (2011).

87 Levendis et al. (2006) pp. 38-39.
} 
puede ser muy ardua. La prueba de la culpa, además, se volvería imposible si el accidente nuclear se debió a caso fortuito.

En cuarto lugar, los límites legales usualmente van unidos al establecimiento de una garantía financiera que cubra el monto del límite. Esta estructura rígida de montos desincentiva el surgimiento y desarrollo de instalaciones nucleares pequeñas, ya que la totalidad de los explotadores cargarán con la contratación de un costoso seguro, incluso por montos superiores a sus riesgos reales.

Finalmente, un límite legal establecido por ley está predestinado a quedarse obsoleto en el tiempo. Pruebas elocuentes de lo anterior son el Convenio de París y la Convención de Viena, que obliga a los Estados parte a establecer un límite no inferior a 7,9 y 5 millones de dólares respectivamente. Cuarenta años más tarde, estos límites legales parecen irrisorios.

Todas estas consideraciones nos llevan a concluir que sería conveniente la derogación del límite legal actual del artículo 60 de la Ley 18.302, así como la modificación del artículo 62 en el sentido de señalar que existe una obligación de contratar una garantía financiera, dejando al arbitrio de los explotadores el cálculo y determinación de los riesgos reales que cubrirán sus pólizas. Si el explotador está obligado a responder sin límite, el explotador será el primer interesado en minimizar sus riesgos obteniendo un seguro que cubra la totalidad de sus potenciales daños.

\subsection{REFORMA EN MATERIA DE PRESCRIPCIÓN DE LA ACCIÓN}

Sin duda, la diversidad y multiplicidad de daños que se pueden producir a causa de un accidente nuclear es muy grande. Por lo mismo, estimamos recomendable que aquellos daños que sean constatables de forma inmediata por la víctima o el legitimado activo para accionar (daños como la muerte de una persona o el daño corporal) tengan un plazo de prescripción menor que aquellos cuya manifestación se produce en el largo plazo, como puede ser el daño derivado de la contaminación de alimentos regados con aguas subterráneas contaminadas con material radiactivo.

De esta forma, tratando de manera distinta situaciones diversas, se lograría que los fines de la prescripción como institución se cumplan de forma cabal y completa. De este modo se aportaría certeza jurídica cargando los legitimados activos con el peso de desplegar un actuar procesal diligente y oportuno para deducir sus acciones. Por otra parte, se concedería un mayor plazo de prescripción respecto de los daños que se manifiesten con posterioridad al accidente.

En cualquier caso, este plazo móvil o ajustable, no debería exceder de un límite razonable ${ }^{88}$, que podría consistir en un límite máximo de 30 años contados desde el accidente nuclear. Este plazo de 30 años sugerido está avalado por la actual tendencia internacional en materia de prescripción. Así lo establece el Protocolo de 1997 que modifica la Convención de Viena ${ }^{89}$; protocolo que Chile aún no ha ratificado. De esta manera, se estará salvaguardando la otra finalidad de la institución de la prescripción, esto es, la certeza jurídica.

88 Stoiber et al. (2003) p. 113.

89 Protocolo de Enmienda de la Convención de Viena sobre Responsabilidad Civil por Daños Nucleares (1997) art. VI. 


\subsection{REFORMAS EN MATERIA DE PREVENCIÓN DEL DAÑo}

Se sugieren finalmente reformas en materia de prevención del daño. En este sentido, se ha criticado que los regímenes internacionales de responsabilidad por daños nucleares carecen de mecanismos de prevención del daño ${ }^{90}$, crítica que es plenamente aplicable al estatuto chileno de responsabilidad nuclear.

Estimamos, que una primera reforma en materia de prevención de daños podría consistir en exigir la publicación periódica (e incluso online) de los niveles de radiación en las inmediaciones de cada instalación nuclear. Estos niveles deberían ser medidos o al menos auditados por entidades independientes. De esta manera, los ciudadanos contarán con parámetros ciertos para acreditar la amenaza de sus derechos y así interponer con éxito un recurso de protección.

Como hemos dicho, no existen acciones nucleares preventivas. Ahora bien, es necesario hacer presente que los mecanismos comunes de la legislación chilena sí podrían cumplir una función preventiva. Nada obsta que, para prevenir daños, se haga uso de la acción de protección constitucional consagrada en el artículo 20 de la Constitución Política de Chile o de las acciones populares consagradas en los artículos 2328 y 2333 del Código Civil. Sin embargo, advertimos algunas dificultades en la interposición de estas acciones en materia nuclear.

La acción de protección constitucional tendrá la grave dificultad para el actor de tener que probar que una determinada instalación está amenazando el legítimo ejercicio de una garantía constitucional. En materia nuclear, esta amenaza puede ser muy difícil de detectar a tiempo sin los instrumentos de medición adecuados.

Por su parte, la acción popular del artículo 2328 del Código Civil tiene la grave limitación de su redacción, que la circunscribe a cosas ubicadas en la parte superior de un edificio que amenacen caída y daño.

Más eficaz nos parece el artículo 2333 del mismo código, que transcribimos para su adecuada comprensión:

Art. 2333. Por regla general, se concede acción popular en todos los casos de daño contingente que por imprudencia o negligencia de alguien que amenace a personas indeterminadas; pero si el daño amenazare solamente a personas determinadas, solo alguna de estas podrá intentar la acción.

La única dificultad que se aprecia es la exigencia legal de acreditar que el demandando (en este caso el explotador de una instalación nuclear) haya incurrido en imprudencia o negligencia. De esta manera, tratándose de una responsabilidad estricta, parece poco aconsejable exigir la prueba de la negligencia en materia de prevención y no en materia de reparación del daño.

En este sentido, una segunda reforma que se propone consiste en incorporar en la Ley 18.302 una acción similar a la del artículo 2333 del Código Civil, eliminando el requisito de la imprudencia o negligencia. Una acción así, se condeciría con la naturaleza estricta de

90 Louka (1993) p. 81. 
este estatuto de responsabilidad, donde la sola acreditación del daño contingente que amenace a personas (determinadas o indeterminadas), sería suficiente para interponer con éxito esta acción. En un juicio de esta naturaleza, no habría inconveniente en solicitar medidas cautelares innominadas (como prejudiciales precautorias o simplemente precautorias) cuando la inminencia del daño vuelva imprudente esperar hasta la dictación de la sentencia para tomar medidas tendientes a evitar un daño nuclear.

\section{CONCLUSIONES}

Si bien Chile no cuenta aún con instalaciones nucleares para la generación de electricidad, Chile sí tiene un estatuto de responsabilidad civil por daños nucleares desde 1984. Este régimen de daños nucleares fue complementado tras la ratificación de Chile de la Convención de Viena sobre Responsabilidad por Daños Nucleares.

Este estatuto vigente pretende regular toda la actividad nuclear en nuestro país, también la que proviene de potenciales futuras plantas de energía nuclear. El análisis de los beneficios y desventajas de promover la energía nuclear en Chile no ha sido el propósito del presente trabajo. Sin embargo, nos parece de provecho una revisión crítica al mismo, a fin de comprenderlo de una mejor manera y sugerir reformas al mismo donde parezca conveniente.

En este sentido, las principales conclusiones de este estudio son:

1. Las normas que conforman el estatuto de responsabilidad chileno por daños nucleares son, principalmente, la Ley 18.302 de 1984 y la Convención de Viena sobre Responsabilidad Civil por Daños Nucleares, ratificada por Chile en 1989.

2. En Chile, el estatuto de responsabilidad por daños nucleares es estricto, es decir, no se requiere acreditar la culpa del explotador para dar lugar a la indemnización.

3. El actual concepto de daño nuclear se restringe a ciertos tipos o categorías de daños. Para lograr una reparación integral de los perjuicios que puedan producirse a raíz de un accidente nuclear se hace imprescindible modificar el concepto de daño nuclear, ampliándolo. Asoman dos posibles reformas alternativas: la primera opción es completar el concepto de daño nuclear, según las observaciones realizadas. La otra alternativa es redefinir daño nuclear no desde el prisma de sus posibles efectos, como ocurre actualmente, sino más bien en base a su causa. Es decir, que se considere daño nuclear todo aquel que provenga directamente de un accidente nuclear.

4. El límite de responsabilidad establecido por la Ley 18.302 de 1984 asciende a 75 millones de dólares. Nos parece conveniente una reforma legal que derogue este límite, haciendo a los explotadores estrictamente responsables de todos los daños que provengan de un accidente nuclear. Al mismo tiempo, parece conveniente una reforma que obligue a las instalaciones nucleares a obtener una garantía financiera que cubra hasta un monto equivalente a la totalidad del potencial daño que puedan causar, y no un monto preestablecido por la ley. 
5. La Ley 18.302 establece un plazo de 10 años, contados desde el accidente nuclear, para hacer valer las acciones de responsabilidad civil por accidentes nucleares. Una forma de perfeccionar el sistema de prescripción de la acción, podría consistir en establecer plazos de prescripción diferenciados en razón del tipo de daño. Así se obtiene una conjunción más perfecta de los fines de la prescripción como institución.

6. En materia de prevención de daño, se sugiere establecer mecanismos de control permanentes y confiables de la radiación nuclear. Asimismo, se propone la consagración de una acción popular por daño contingente o inminente, similar a la establecida en el artículo 2333 del Código Civil, pero con la diferencia de que no sea necesario acreditar un actuar negligente o imprudente del explotador. Es decir, una acción popular de responsabilidad preventiva que sea al mismo tiempo estricta o sin culpa.

\section{BIBLIOGRAFÍA CITADA}

Abeliuk Manasevich, René (2001): Las Obligaciones (Santiago, Editorial Jurídica de Chile, 4a edición) $528 \mathrm{pp}$.

Alessandri Rodríguez, Arturo (1943): De la responsabilidad extracontractual en el Derecho Civil chileno (Santiago, Imprenta Universitaria) 716 pp.

Barrientos Zamorano, Marcelo (2008): "Del daño moral al daño extrapatrimonial: la superación del pretium doloris", Revista Chilena de Derecho, vol. XXXV N 1: pp. 85-106.

Barros Bourie, Enrique (2006): Tratado de responsabilidad extracontractual (Santiago, Editorial Jurídica de Chile) 1.230 pp.

BBC (2011): How does Fukushima differ from Chernobyl? Disponible en: <http://www.bbc. co.uk/news/world-asia-pacific-13050228?print=true> [fecha de consulta 20 de noviembre de 2011].

Caro Manso, Rafael (1995): Historia Política de la Ciencia Nuclear. Disponible en <http:// ruc.udc.es/dspace/bitstream/2183/8913/1/CC20art4ocr.pdf> [fecha de consulta: 20 de septiembre de 2012].

Codarech (2006): "Energía nuclear: ¿agonía o resurrección?”, Infraestructura y medio ambiente, vol. XXIV Nº 108: pp. 308-313.

Comisión Chilena de Energía Nuclear: "Reactores Nucleares". Disponible en <http:// www.cchen.cl/index.php?option=com_content\&task=view\&id=250\&Itemid=2> [fecha de consulta: 19 de noviembre de 2011].

Cooper, Mark (2011): Nuclear liability: The market-based, post-Fukushima case for ending Price-Anderson. Disponible en: <http:/www.thebulletin.org/web-edition/features/ nuclear-liability-the-market-based-post-fukushima-case-ending-price-anderson $>$ [fecha de consulta: 19 de noviembre de 2011].

Corral Talciani, Hernán (2003): Lecciones de responsabilidad civil extracontractual (Santiago, Editorial Jurídica de Chile) 423 pp.

DAvies, Lincoln L. (2011): "Beyond Fukushima: Disasters, nuclear energy, and energy law”, Brigham Young University Law Review, pp. 1.937-1.989. 
Domínguez Hidalgo, Carmen (2000): El daño moral (Santiago, Editorial Jurídica de Chile) $782 \mathrm{pp}$.

Eisenhower, Dwight D. (1953): "Atoms for peace". Disponible en: <http://www.iaea.org/ About/history_speech.html> [fecha de consulta: 19 de noviembre de 2011] Traducción de los autores.

Elorriaga de Bonis, Fabián (2011): “Del día de inicio del plazo de prescripción de una acción indemnizatoria cuando el perjuicio se ha manifestado con posterioridad al hecho que lo origina”, en: Corral Talciani, Hernán (edit.), Prescripción extintiva - Estudios sobre su procedencia y funcionamiento en derecho público y privado (Santiago, Universidad de los Andes) pp. 25-61.

Fernández de Gatta SÁnchez, Dionisio (2007): Derecho ambiental: aspectos generales sobre la protección jurídica del medio ambiente. Disponible en: <http://dialnet.unirioja.es/ descarga/articulo/1010577.pdf> [fecha de consulta: 22 de septiembre de 2012] 11 pp.

Fondo Monetario Internacional (2011): "Derechos Especiales de Giro (DEG)". Disponible en: <http://www.imf.org/external/np/exr/facts/spa/sdrs.htm> [fecha de consulta: 22 de noviembre de 2011]. Hidalgo Capitán, Antonio Luis (2011): Economía politica global - Globalización, gobernanza y crisis. Disponible en: <http://www.eumed. net/libros/2011b/942/> [fecha de consulta: 22 de septiembre de 2012]. $296 \mathrm{pp}$.

Honorable Junta de Gobierno de Chile (1982): Oficio 6583/188 (R) de 15 de octubre de 1982.3 pp.

Honorable Junta de Gobierno de Chile (1989): Acta $N^{\circ} 30 / 89$ de 26 de septiembre de 1989. Disponible en: <http://historiapolitica.bcn.cl/historia_legislativa/visorPdf?id=1 $0221.3 / 34631 \& \mathrm{ref}=\left[\mathrm{secc}=\right.$ historia_legislativa, periodo=buscar.php? $\mathrm{b}=3$, term $=$ Acta $\mathrm{N}^{\circ}$ 30/89, pagina $=1$ ] > [fecha de consulta: 23 de noviembre de 2011].

Hunter, David, Salzman, James y Zaelke, Durwood (2007): International Environmental Law and Policy (Nueva York, Foundation Press, $3^{\mathrm{a}}$ edición) 1.613 pp.

IAEA (2011): Report of the Japanese government to the IAEA Ministerial Conference on nuclear safety - The accident at TEPCO's Fukushima nuclear power stations. Disponible en: <http://fukushima.grs.de/sites/default/files/NISA-IAEA-Fukushima_2011-06-08.pdf> [fecha de consulta: 20 de noviembre de 2011].

IAEA (2012): "Nuclear power reactors in the world", Reference data series No. 2. Disponible en: <http://www-pub.iaea.org/books/iaeabooks/8954/Nuclear-Power-Reactors-in-theWorld-2012-Edition> [fecha de consulta: 22 de septiembre de 2012] 86 pp. 10-11.

Kessides, Ioannis N. (2010): "Nuclear power: Understanding the economic risk and uncertainties”, Energy Policy, vol. 38: pp. 3.849-3.864.

Levendis, John; Block, Walter y Morrel, Joseph (2006): "Nuclear Power", Journal of Business Ethics, vol. $67 \mathrm{~N}^{\circ} 1$ : pp. 37-49.

LoukA, Elli (1993): "Bringing polluters before transnational courts: Why industry should demand strict and unlimited liability for the transnational movements of hazardous and radioactive waste", Denver Journal of International Law and Policy, vol. $22 \mathrm{~N}^{\circ} 1$ : pp. 63106. 
Ministerio de Energía (2011): Balance Anual. Disponible en: <http://www.injuv.gob.cl/ mensaje_presidencial/2011/content/ministerios/pdf/energia.pdf> [fecha de consulta: 26 de noviembre de 2011].

Ministerio de Minería (1983): Informe Técnico acompañado a la Honorable Junta de Gobierno durante la tramitación proyecto de ley de seguridad nuclear. El Informe ha sido adjuntado a la Historia de la Ley 18.302.

Monroy Cabra, Marco Gerardo (1978): Derecho de los tratados (Bogotá, Editorial TEMIS Librería) 317 pp.

OECD-NEA (1990): Paris Convention - Decisions, recommendations, interpretations 27 pp. Disponible en: <http://www.oecd-nea.org/law/paris-convention-dec-rec-int.pdf> [fecha de consulta: 24 de marzo de 2012].

OECD-NEA (2011a): "Fukushima”, NEA News, no. 29.1. pp. 6-10. Disponible en: <http://www.oecd-nea.org/nea-news/2011/29-1/29-1-int-e.pdf> [fecha de consulta: 20 de noviembre de 2011].

OECD-NEA (2011b): "Nuclear operator liability amounts \& financial security limits as of June 2011”. Disponible en: <http://www.oecd-nea.org/law/2011-table-liability-coverage-limits.pdf> [fecha de consulta: 21 de noviembre de 2011].

Olivares Gallardo, Alberto (2010): "Consideraciones sobre los residuos radioactivos en el debate de la energía nuclear y su inclusión en el modelo energético de Chile”, Revista Chilena de Derecho, vol. XXXVII N 3: pp. 429-458.

Owen, Anthony D. (2011): "The economic viability of nuclear power in a fossil-fuel-rich country: Australia”, Energy Policy, vol. 39: pp. 1.305-1.311.

Piñera Echenique, Sebastián (2011): Mensaje al País del Presidente de la República de Chile en el inicio de la legislatura ordinaria del Congreso Nacional, 21 de mayo del año 2011. Disponible en: <http://www.gob.cl/media/2011/05/Mensaje-Presidencial-21-deMayo-2011.pdf> [fecha de consulta: 26 de noviembre de 2011].

Presidencia de la República de Chile (1982): Mensaje del Ejecutivo a la Honorable Junta de Gobierno en relación al Proyecto de Ley sobre Seguridad Nuclear y Radioprotección. Boletín 292-08 de 6 de octubre de 1982. 2 pp.

Rosa, Eugene A. y Rice, James (2004): "Public reaction to nuclear power siting and disposal”, en: Elsevier, Encyclopedia of Energy, vol.5 pp. 181-194.

Ruz LÁrtiga, Gonzalo (2008): “La reparación integral del daño: ¿mito o realidad?”, Estudios de Derecho Civil IV: pp. 661-677.

Secretaría de Legislación de la Honorable Junta de Gobierno de Chile (1982): Informe al proyecto de ley de seguridad nuclear y radioprotección de 13 de diciembre de 1982. $166 \mathrm{pp}$.

Silva Bascuñán, Alejandro (2000): Tratado de Derecho Constitucional (Santiago, Editorial Jurídica de Chile) Tomo VII, 361 pp.

Sovacool, Benjamin K. (2008): "Valuing the greenhouse gas emissions from nuclear power: A critical survey”, Energy Policy, vol. 36: pp. 2950-2963.

Stoiber, Carlton, Baer, Alec, Pelzer, Nortbert y Tonhauser, Wolfram (2003): Handbook on Nuclear Law (Viena, International Atomic Energy Agency) 168 pp. 
Teräväinen, Tuula, Lehtonen, Markku y Martiskainen, Mari (2011): “Climate Change, energy security, and risk-debating nuclear new build in Finland, France and the UK”, Energy Policy, vol. 39: pp. 3.434-3.442.

The Guardian (2011): "Angela Merkel switches off seven nuclear power plants". Disponible en: <http://www.guardian.co.uk/world/2011/mar/15/germany-merkel-switchesnuclear-power-off> [fecha de consulta: 24 de marzo de 2012].

Vergara Bezanilla, José Pablo (2011): “Aceptación jurisprudencial de la doctrina de que la prescripción extintiva de la responsabilidad extracontractual empieza a correr desde la perpetración del acto ilícito y no a contar de la producción del daño", en: Corral Talciani, Hernán (edit.), Prescripción extintiva - Estudios sobre su procedencia y funcionamiento en derecho público y privado (Santiago, Universidad de los Andes) pp. 25-61.

\section{NORMAS CITADAS}

Australian Radiation Protection and Nuclear Safety Act 1998 (Cth) s 10(1)(b).

Código Civil de Chile.

Constitución Política de la República de Chile.

Convenio de Bruselas Complementario del Convenio de París sobre Responsabilidad Civil en Materia de Energía Nuclear, adoptado el 31 de enero de 1963 y modificado el 28 de enero de 1964, el 16 de noviembre de 1982 y el 12 de febrero de 2004 (no ratificado por Chile).

Convenio de París sobre Responsabilidad Civil en Materia de Energía Nuclear, adoptado el 29 de julio de 1960 (no ratificado por Chile).

Decreto No 8, Ministerio de Relaciones Exteriores, de 10 de enero de 2005, Promulga la Convención de Asistencia en caso de Accidente Nuclear o Emergencia Radiológica. Diario Oficial, 12 de abril de 2005.

Decreto No 12. Aprueba el Reglamento para el Transporte Seguro de Materiales Radioactivos. Diario Oficial, 10 de junio de 1985.

Decreto No 87, Ministerio de Minería, de Aprueba el reglamento de protección física de las instalaciones radiactivas. Diario Oficial, 9 de marzo de 1985.

Decreto No 133, Ministerio de Salud, de 23 de agosto de 1984. Aprueba el Reglamento que Autoriza las Instalaciones Radioactivas o Equipos Generadores de Radiaciones Ionizantes y su Personal de Operación. Diario Oficial, 23 de agosto de 1984.

Decreto No 272, Ministerio de Relaciones Exteriores, de 3 de marzo de 1997, Promulga la Convención sobre Seguridad Nuclear. Diario Oficial, 3 de junio de 1997.

Decreto No 381, Ministerio de Relaciones Exteriores, de 5 de mayo de 1981, Promulga la Convención de Viena sobre el Derecho de los Tratados. Diario Oficial, 22 de junio de 1981.

Decreto No 381, Ministerio de Relaciones Exteriores, de 27 de diciembre de 2005, Aprueba la Convención sobre la Pronta Notificación de Accidentes Nucleares. Diario Oficial, 25 de abril de 2006. 
Decreto No 1.121, Ministerio de Relaciones Exteriores de 30 de octubre de 1994, Aprueba la Convención sobre Protección Física de los Materiales Nucleares. Diario Oficial, 17 de octubre de 1994.

Decreto No 1.212, Ministerio de Relaciones Exteriores, de 30 de septiembre de 1993, Aprueba el Protocolo Común relativo a la aplicación de la Convención de Viena y del Convenio de París, sobre Responsabilidad Civil por Daños Nucleares. Diario Oficial, 17 de octubre de 1994.

Decreto Ley N².222, Ministerio de Defensa Nacional, de 21 de mayo de 1978, Sustituye Ley de Navegación. Diario Oficial, 31 de mayo de 1978.

Decreto Ley No 2.224, Ministerio de Minería, de 25 de mayo de 1978, Crea la Comisión Nacional de Energía Nuclear. Diario Oficial, 8 de junio de 1978.

Decreto Supremo $N^{\circ}$ 18, Ministerio de Relaciones Exteriores, de 8 de enero de 1990, Aprueba Convención de Viena sobre Responsabilidad Civil por Accidentes Nucleares. Diario Oficial, 8 de marzo de 1990.

Ley $N^{\circ}$ 16.319. Ley que Crea la Comisión Chilena de Energía Nuclear. Diario Oficial, 23 de octubre de 1965.

Ley N 18.916. Código Aeronáutico. Diario Oficial, 8 de febrero de 1990.

Ley N ${ }^{\circ}$ 18.302. Ley de Seguridad Nuclear. Diario Oficial, 2 de mayo de 1984.

Ley $N^{\circ}$ 19.300. Ley sobre Bases Generales del Medio Ambiente. Diario Oficial, 9 de marzo de 1994.

Protocolo de Enmienda de la Convención de Viena sobre Responsabilidad Civil por Daños Nucleares, aprobada en septiembre de 1997.

\section{JURISPRUDENCIA CITADA}

Corte Suprema (1953), 14 de abril de 1953, Revista de Derecho y Jurisprudencia, t. 50, sec. $4^{\mathrm{a}}$, pp. 40 y ss.

Corte Suprema (2006), 30 de noviembre de 2006. Disponible en: <http://www.poderjudicial.cl/juris_pjud/jurisprudencia2.php> [fecha de consulta: 22 de septiembre de 2012].

Corte Suprema (2009a), 2 de julio de 2009. Disponible en: <http://www.poderjudicial.cl/ juris_pjud/jurisprudencia2.php> [fecha de consulta: 22 de septiembre de 2012].

Corte Suprema (2009b), 13 de julio de 2009. Disponible en: <http://www.poderjudicial. cl/juris_pjud/jurisprudencia2.php> [fecha de consulta: 22 de septiembre de 2012].

Corte Suprema (2012), 13 de junio de 2012; No Identificador Legal Publishing CL/ JUR/1092/2012. 